San Jose State University

SJSU ScholarWorks

Master's Theses

Master's Theses and Graduate Research

Fall 2009

\title{
21st century change in sea-level pressure investigated in North Pacific Ocean.
}

Emerson N. LaJoie

San Jose State University

Follow this and additional works at: https://scholarworks.sjsu.edu/etd_theses

\section{Recommended Citation}

LaJoie, Emerson N., "21st century change in sea-level pressure investigated in North Pacific Ocean." (2009). Master's Theses. 3967.

DOI: https://doi.org/10.31979/etd.u2ed-uawy

https://scholarworks.sjsu.edu/etd_theses/3967

This Thesis is brought to you for free and open access by the Master's Theses and Graduate Research at SJSU ScholarWorks. It has been accepted for inclusion in Master's Theses by an authorized administrator of SJSU ScholarWorks. For more information, please contact scholarworks@sjsu.edu. 


\title{
$21^{\text {st }}$ CENTURY CHANGE IN SEA-LEVEL PRESSURE INVESTIGATED IN NORTH PACIFIC OCEAN
}

\author{
A Thesis \\ Presented to \\ The Faculty of the Department of Meteorology \\ San José State University \\ In Partial Fulfillment \\ of the Requirements for the Degree \\ Master of Science
}

by

Emerson N. LaJoie

August 2009 
UMI Number: 1478572

All rights reserved

INFORMATION TO ALL USERS

The quality of this reproduction is dependent upon the quality of the copy submitted.

In the unlikely event that the author did not send a complete manuscript and there are missing pages, these will be noted. Also, if material had to be removed, a note will indicate the deletion.

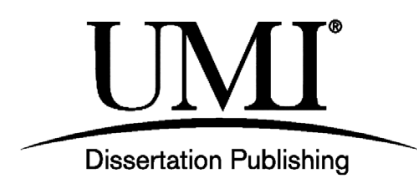

UMI 1478572

Copyright 2010 by ProQuest LLC.

All rights reserved. This edition of the work is protected against unauthorized copying under Title 17, United States Code.

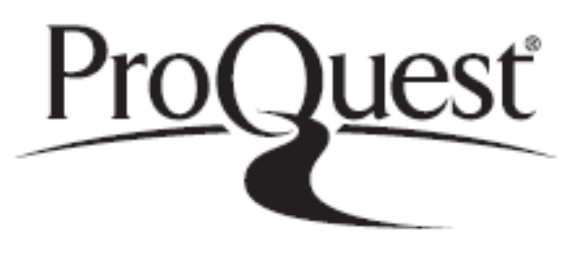

ProQuest LLC

789 East Eisenhower Parkway

P.O. Box 1346

Ann Arbor, Ml 48106-1346 
(C) 2009

Emerson N. LaJoie

ALL RIGHTS RESERVED 


\title{
SAN JOSÉ STATE UNIVERSITY
}

The Undersigned Thesis Committee Approves the Thesis Titled

$21^{\text {st }}$ CENTURY CHANGE IN SEA-LEVEL PRESSURE INVESTIGATED IN NORTH PACIFIC OCEAN

\author{
by \\ Emerson N. LaJoie
}

APPROVED FOR THE DEPARTMENT OF METEOROLOGY

$\overline{\text { Dr. Eugene C. Cordero, }} \quad$ Department of Meteorology Date

$\overline{\text { Dr. Alison F. C. Bridger, Department of Meteorology Date }}$

\begin{tabular}{lll}
\hline Dr. Jerry L. Steffens, & Department of Meteorology
\end{tabular}

APPROVED FOR THE UNIVERSITY

Associate Dean $\quad$ Office of Graduate Studies and Research Date 


\title{
ABSTRACT \\ $21^{\text {st }}$ CENTURY CHANGE IN SEA-LEVEL PRESSURE INVESTIGATED IN NORTH PACIFIC OCEAN
}

\author{
by Emerson N. LaJoie
}

Mean changes in the climatology of $21^{\text {st }}$ century annual variance of the sea-level pressure field in the North Pacific Ocean were investigated from all climate models that were used in the Intergovernmental Panel on Climate Change (IPCC) Fourth Assessment Report (AR4). In several specific areas, a statistically significant increase in the annual variance of sea-level pressure was simulated for the $21^{\text {st }}$ century in three emission scenarios; however, the magnitude of change did not follow the forcing. The results indicate increased low-pressure activity for the Bering Sea, Bering Strait, Alaska, Gulf of Alaska, Canadian Rocky Mountains, and the west coast of the U.S. A separate study investigated the potential correlation between the magnitude of change predicted by individual models and the models' equilibrium climate sensitivity value. Statistically significant, positively correlated regions from each emission scenario over the eastern portions of the North Pacific Ocean were found. The results indicated that, in the regions of Alaska, the Gulf of Alaska, the Canadian Rocky Mountains, and the west coast of the U.S., the magnitude of change in the annual variance of sea-level pressure could be predicted by the model's sensitivity to $\mathrm{CO}_{2}$ forcing. The sensitivity and robustness of the results from each study were examined using two different multimodel groups. 


\section{ACKNOWLEDGEMENTS}

I am indebted to the members of my committee for their invaluable insights, guidance, support, and deliberation over my thesis. I dedicate the motivation for this thesis to them and their efforts. I truly enjoyed my research and learning experiences under their erudition. I am honored to have been able to collaborate with them on such interesting topics as the ones addressed by my thesis. I would like to extend additional appreciation to my advisor, my friend, and my role model, Dr. Eugene Cordero. Without his patience and good humor, I would have been at a loss.

Without the support of a reliable computing infrastructure, this thesis would not have been possible. I owe due thanks to Mike Voss for keeping my computing issues to a bare minimum.

To those colleagues who imbued me with their wisdom, time, and kindness, I am grateful. With their support and generosity of spirit, I was able to accomplish this coveted goal.

I owe my family a great deal of gratitude for they were understanding and supportive of my decisions to, at times, forego their needs in lieu of mine. This gratitude is especially directed to my husband. His compassion and breadth of resilience regarding my struggles and successes are unparalleled. His unwavering support throughout every step of my experience made this thesis a wonderful journey. 


\section{TABLE OF CONTENTS}

LIST OF TABLES ........................................................................................ vii

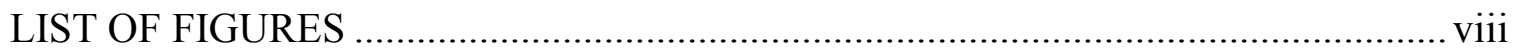

1. Introduction and Review of Storm Track Response to Increased Forcing ................. 1

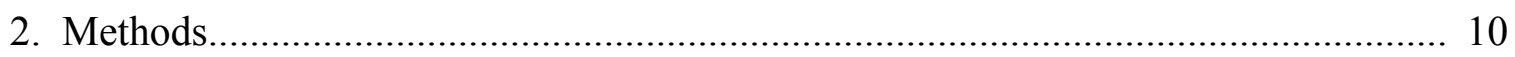

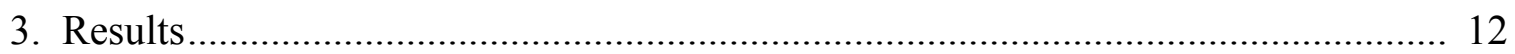

a. Two multimodel summaries of the mean change in annual variance .................... 12

b. Characteristics of annual variability and tnterpretation of 3 a findings................ 20

c. Correlation between the magnitudes of change in $\triangle A V_{21 C}$ and ECS values ......... 24

4. Discussion and Future Work................................................................................ 30

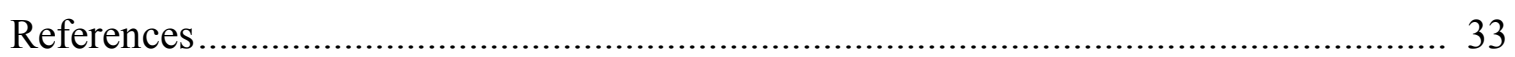




\section{LIST OF TABLES}

Table 1. List and details of the global climate models used in this study. ................. 4 


\section{LIST OF FIGURES}

Fig. 1. Top (bottom) panel indicates the model with the maximum increase (decrease) in spatially-averaged $\triangle A V_{21 C}$ calculated within the red box (Region 1) for the A2 scenario.

Fig. 2. Same as in Fig. 1 except for A1B scenario. ...........................................14

Fig. 3. Same as in Fig. 1 except for B1 scenario. .............................................. 15

Fig. 4. Map of eight regions in the NPO that were used for the multimodel group statistical analyses discussed in Section 3a. ........................................... 17

Fig. 5. Same as in Fig. 4 except select-multimodel group. ..................................19

Fig. 6. The A1B scenario multimodel-mean, annually-averaged MSLP for

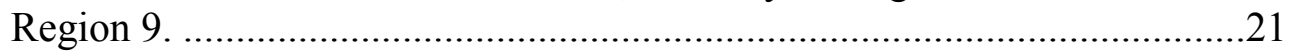

Fig. 7. The A1B scenario multimodel-mean of minimum SLP values. .................22

Fig. 8. The B1 scenario multimodel-mean of annually-averaged MSLP for

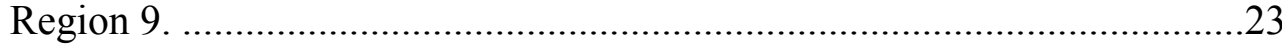

Fig. 9. An example region of positive correlation (orange box) from the selectmultimodel study of the A2 scenario. .....................................................26

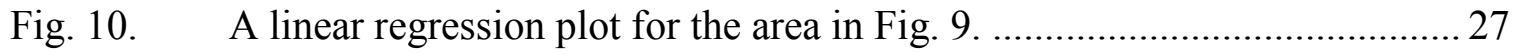

Fig. 11. Areas with positive (orange) and negative (green) correlations from the

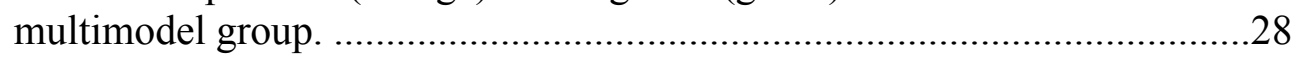

Fig. 12. Same as in Fig. 11 except for select-multimodel group. ............................29 


\section{Introduction and Review of Storm Track Response to Increased Forcing}

This thesis investigates the $21^{\text {st }}$ century forcing effects of increased atmospheric $\mathrm{CO}_{2}$ levels on the seasonal climatology of the SLP field over the North Pacific Ocean (NPO). Two different multimodel groups (explained below) were used in the investigation and helped to determine the sensitivity of the results. The research presented in this thesis divides into three elements: research on the changes in the climatology of the SLP field, investigation of model variability, and exploration of correlations between intrinsic model properties and output.

To research the future climatology of the SLP field, the metric of calculating the percent difference in the first and last 30-year averages of annual variance was used. Annual variance is calculated from simulated monthly mean sea-level pressure (MSLP) values. The results from this metric revealed wide-ranging differences between the models. The investigation into model variability and robustness of the results was led by the comparison of two multimodel groups.

The multimodel group is comprised of every model available from the Intergovernmental Panel on Climate Change (IPCC) 2007 Fourth Assessment Report (AR4). The select-multimodel group members are a subclass of the multimodel group. They are chosen based on their skillful simulation of $20^{\text {th }}$ century observations. The two multimodel groups help to examine model-to-model variability, robustness of the results, and the sensitivity of the results to model choice. To examine the influence model parameters may have on model output, a corresponding study explores the relationship between the magnitude of change predicted by the model) and their sensitivity to $\mathrm{CO}_{2}$ forcing. 
There is limited research published on the topic of climate-related changes to the annual variance of MSLP over the NPO. The metric of variance, however, parallels research published on investigations into storm tracks and their response to increased greenhouse gas (GHG) forcing. The main points from the literature on storm tracks and climate change for the NPO are summarized in the following passages.

While general agreement exists on how large-scale features, such as the jet stream, will respond to increased forcing (e.g., Archer and Caldeira 2008; Bengtsson et al. 2006, Randall et al. 2007), consensus is not found on topics such as relocation, frequency, intensity, and distribution changes to storm tracks (e.g., Lambert and Fyfe 2006; Pinto et al., 2007). Storm tracks are identified as areas that experience frequent seasonal passing of storm activity associated with middle latitude cyclogenesis. In the passages that follow, it will become evident that research conclusions regarding the future changes to frequency, distribution, and/or intensity of storm tracks are inconsistent.

The westerly wind regimes, or jet streams, are instrumental in the development of baroclinic wave activity in the middle latitudes. Strong baroclinic disturbances develop from steep temperature gradients which occur with a meridional jet stream. Baroclinic disturbances play a key role in the conversion and transport of energy in the atmosphere. Horizontal temperature gradients and thermal wind balance are determinants of how geostrophic winds will vary with height, and thus determine the characteristics of the pressure and temperature fields. Regions that are dense with storm tracks are most frequently observed in regions that are disturbed by baroclinic disturbances, for example, the wintertime domain of the Aleutian Low. 
In recent literature, a general consensus among researchers indicates a poleward shift of the westerly wind regimes in response to a warming climate (e.g., Archer and Caldeira 2008). The shift is occurring in both hemispheres and storm tracks are following (e.g., Randall et al. 2007). The Hadley Cell is reported to be weakening and also shifting poleward (Lu et al. 2007, 2008). As tropospheric temperature rises due to increasing GHG concentrations, the NH polar regions are warming faster than the tropics, causing the equator-to-pole (or meridional) temperature gradient to decrease. The maximum meridional temperature gradient is occurring at higher latitudes, and the jet stream is responding by shifting poleward and weakening (e.g., Bengtsson et al. 2006; Yin 2005). Higher latitudes are expected to experience increased storm frequency and precipitation (Bengtsson et al. 2006; Haiyan et al. 2008; Salathé 2006). Middle latitudes may see increased storm intensity but reduced storm frequency (Lambert and Fyfe 2006). As the Hadley Cell responds to increased forcing, the subtropics are expected to experience less annual precipitation leading to desertification (Lu et al. 2007, 2008).

Bengtsson et al. (2006, hereafter BHR06) reported on the influence climate change may have on storm tracks. Using the MPI model (See Table 1 for model information) and the A1B scenario, BHR06 concluded that changes in storm track activity are directly correlated to changes in sea-surface temperature (SST). They also concluded a poleward translation of storm tracks during boreal winter. BHR06 found weakening along the southern domain of the North Pacific storm track $\left(\sim 30^{\circ} \mathrm{N}\right)$ and at the starting zone of the storm track over Japan. Conversely, an increase in storm activity was simulated over the northeastern Pacific. For this region, their results indicated that while the 
frequency of storms may increase, storm intensity will not.

Table 1. List of climate models used in this study. ECS values are provided as available from the IPCC AR4. Asterisk (dash) indicates monthly mean sea-level pressure data was (was not) available from that model for the scenario listed. Bold entries indicate the models chosen for the select-multimodel group based on the index of model performance developed by Reichler and Kim (2008).

\begin{tabular}{llcccc}
\multicolumn{1}{c}{ Short name } & \multicolumn{1}{c}{ Model, Origin } & ECS $\left({ }^{\circ} \mathrm{C}\right)$ & A2 & A1B & B1 \\
INMCM & INM-CM3.0, Russia & 2.1 & $*$ & $*$ & $*$ \\
NCAR & PCM, United States & 2.1 & $*$ & $*$ & $*$ \\
IAP & FGOALS-g1.0, China & 2.3 & - & $*$ & $*$ \\
NCAR2 & NCAR-CCSM3, United States & 2.7 & $*$ & $*$ & $*$ \\
GISSEH & GISS-EH, United States & 2.7 & - & $*$ & - \\
GISS & GISS-ER, United States & 2.7 & $*$ & $*$ & $*$ \\
GFDL0 & GFDL-CM2.0, United States & 2.9 & $*$ & $*$ & $*$ \\
CSIRO30 & CSIRO-Mk3.0, Australia & 3.1 & $*$ & $*$ & $*$ \\
ECHO & ECHO-G, Germany/Korea & 3.2 & $*$ & $*$ & $*$ \\
MRI & MRI-CGCM2.3.2, Japan & 3.2 & $*$ & $*$ & $*$ \\
HADCM3 & UKMO-HadCM3, United Kingdom & 3.3 & $*$ & $*$ & $*$ \\
CCC47 & CGCM3.1 (T47), Canada & 3.4 & $*$ & $*$ & $*$ \\
CCC63 & CGCM3.1 (T63), Canada & 3.4 & - & $*$ & $*$ \\
MPI & ECHAM5/MPI-OM, Germany & 3.4 & $*$ & $*$ & $*$ \\
GFDL1 & GFDL-CM2.1, United States & 3.4 & $*$ & $*$ & $*$ \\
MEDRES & MIROC3.2(medres), Japan & 4 & $*$ & $*$ & $*$ \\
HIRES & MIROC3.2(hires), Japan & 4.3 & - & $*$ & $*$ \\
IPSL & IPSL-CM4, France & 4.4 & $*$ & $*$ & $*$ \\
HADGEM1 & UKMO-HadGEM1, United Kingdom & 4.4 & $*$ & $*$ & - \\
BCCR & BCCR-BCM2.0, Norway & n.a. & $*$ & $*$ & $*$ \\
CNRM & CNRM-CM3, France & n.a. & $*$ & $*$ & $*$ \\
CSIRO35 & CSIRO-Mk3.5, Australia & n.a. & $*$ & $*$ & $*$ \\
GISSAOM & GISS-AOM, United States & n.a. & - & $*$ & $*$ \\
SXG & INGV-SXG, Italy & n.a. & $*$ & $*$ & -
\end{tabular}


BHR06 experiments showed a robust connection between SST and storm track changes. They indicate that the maximum SST warming that occurs in the eastern Pacific signals an El Niño-like condition. This result led BHR06 to examine the influence of the ENSO in their climate change experiment. They concluded that the warming trend from the $20^{\text {th }}$ century to the $21^{\text {st }}$ century is suggestive of the underlying ENSO variability in the MPI model. BHR06 concluded that the change in storm distribution is mainly related to changes in SST patterns. Changes in SST patterns are related to changes in atmospheric circulation patterns hence, increased GHG concentrations are changing atmospheric circulation patterns (BHR06).

Yin (2005, hereafter Y05) examined changes to storm tracks with 15 coupled GCMs that were also included in the 2007 IPCC AR4. Storm tracks in the $20^{\text {th }}$ century were compared to the A1B scenario for the $21^{\text {st }}$ century. Y05 title their paper to indicate a consistent poleward shift was found in each hemisphere for the December, January, and February (DJF) winter storm track, however, not all of the models showed significant changes. The Y05 study included four models that did not show a poleward shift of the DJF storm tracks: INMCM, GISSAOM, MPI, and MRI. Additionally, the June, July, August (JJA) storm track is weakened and shifted poleward in only 9 of 15 models. The different results given by the models were not further addressed in Y05.

Y05 suggested that changes in the DJF storm track are due to three main factors, which appeared in each models' simulation. The first factor was an increase in the temperature of the upper-troposphere in tropical regions due to a decrease in the moist adiabatic lapse rate during DJF and JJA. Second, an increase in NH high latitude surface 
temperatures was observed due to a decrease and retreat of sea ice. Third, a minor change in surface temperature was also observed at Southern Hemisphere high latitudes due to the thermal inertia of the Southern Ocean.

Pinto et al. (2007, hereafter P07) used the MPI model to analyze storm tracks in three scenarios: A2, A1B, and B1. They reported that the magnitude of change detected was dependent on the change in forcing imposed in each simulation. The main change simulated for the winter half year (October to March), was a reduction of storm activity in the storm track exit region in the Pacific Northwest. P07 reported an overall decrease in mid-latitude cyclone density for the NH. Along the Canadian coast and east of Japan, the decreases were more significant. Regarding mid-latitude cyclone frequencies in the NPO, P07 reported that changes were insignificant. They also reported very little change in the future position of the NPO storm tracks.

Lambert and Fyfe (2006, hereafter LF06) provided an in-depth study of 15 GCMs that were involved in the 2007 IPCC AR4. They examined changes in the November to March, mid-latitude cyclone frequencies, and strengths, for several simulation scenarios, including A2, A1B, and B1. They tracked storms via the minima value found from daily averaged mean sea-level pressure (MSLP) data. They concluded that with each increase in emission scenario, a progression of decreasing storms and increasing intensity can be expected for the future. This result indicates that as the magnitude of GHG forcing increases, so does the magnitude of the changes in storm tracks. LF06 did not find changes to the geographical position of storm tracks. LF06 highlighted that their results oppose the assertion made by BHR06 that increased temperature at the surface leads to increased 
water vapor, which in turn increases the available energy for more frequent storm events (BHR06).

Teng, Washington, and Meehl (2008, hereafter TWM08) investigated the A1B scenario with the NCAR2 model, and found a significant increase in January, February, and March mid-latitude cyclone frequency along the west coast of the U.S., and a decrease in Alaska. Their findings are not in accord with the findings of LF06, who stated that models are generally simulating fewer, but more intense, cyclones with no relocation of storm tracks in both hemispheres. This contrast between researchers' result is highlighted here because it exemplifies the variability that can be found between two studies using the same GCM (both studies used the NCAR2 model). TWM08 reported that increased storm activity results from lower troposphere warming, together with warming in the upper troposphere over tropical regions and cooling over higher latitudes in the stratosphere.

TWM08 study showed that future anomalies in the zonal wind over the Pacific would be negative in the Northern Pacific and positive in the subtropics. Their result suggested that the exit region of the jet stream moves southeastward, which would favor cyclonic development along the west coast of the U.S. These findings are similar to Y05, with the exception that TWM08 reported more extratropical cyclones at higher latitudes.

Greeves et al. (2006, hereafter G06) noted that coupled models exhibit cold biases in tropical-Pacific SST distribution, which affect storm tracks in the region. G06 used the Hadley Centre models and stated HadGEM1 (a coupled GCM) is known to lack the variability normally associated with the ENSO. They concluded that a northward shift of 
storm activity is likely for the western portions of the NPO. They also concluded that this result is related to the cold equatorial SST bias that mimics La Niña anomalies.

Lu et al. (2008, hereafter LCF08) investigated the effects of El Niño-like forcing versus GHG forcing in the A2 scenario. They used the A2 simulations from the GFDL CM2.1 coupled GCM. They made a comparison between the Hadley Cell response to GHG forcing versus El Niño-like forcing (given as increased SST in the eastern tropical portion of the Pacific Ocean). The Hadley Cell responded to increased GHG forcing in the model by weakening and shifting poleward. The maximum meridional temperature gradient occurred at higher latitudes and thus strengthened the poleward flank of the jet. When the model used El Niño-like forcing, the Hadley Cell responds by contracting and strengthening, thus, drawing the jet stream equatorward. This contraction of the tropical circulation is also seen in observations (LCF08).

Observed with GHG-induced warming trends, precipitation at the equator increased, whereas between $25^{\circ}$ to $45^{\circ} \mathrm{N}$ precipitation decreases (LCF08). The increase could be credited to the increased atmospheric moisture content, and would occur regardless of the expansion of the Hadley Cell (LCF08). Conversely, the tropical response to El Niño-like forcing was amplified by a contracted and strengthened Hadley Cell. The subtropical dry zone (defined as where precipitation equals evaporation) is tightly coupled to the descending branch of the Hadley Cell, and as reported by LCF08, there are conflicting results on its future position.

From this literature review, it is clear the models do not entirely agree on the future changes to the frequency, intensity, and distribution of storm tracks. It is possible 
that parameterizations that are used by GCMs are the contributing factor. Currently, there is little evidence to support a link between parameterized cloud processes and model-to-model variability regarding storm tracks. Soden and Held (2006) showed that models vary widely due to parameterizations that are used for sub-grid processes such as cloud processes, radiative processes, and boundary-layer processes. In their study, Soden and Held (2006) found that the majority of uncertainties from model output of global mean surface temperature results from cloud processes.

Cloud processes have been linked to $\mathrm{CO}_{2}$ forcing. The effect of different cloud parameterizations was examined by Sanderson et al. (2008). They identified two specific parameterizations that played a primary role in determining model sensitivity to $\mathrm{CO}_{2}$ forcing: the entrainment coefficient and the icefall speed. The direct link between cloud microphysics and model sensitivities will not be explored in this thesis. However, it is worth noting the origin of model uncertainty because identifying sources responsible for the variability between models is an opportunity to understand and improve the physical processes that are simulated by models, as well as identify the factors that are most influential on model performance.

Two popular methods are used by researchers to determine future changes to storm tracks: examine the vorticity from the geopotential height field at either $500 \mathrm{hPa}$ or $850 \mathrm{hPa}$; or locate minima in the MSLP field and then map trajectories from frontogenesis to frontalysis. From these methods researchers can extract the changes in frequency, intensity, and distribution of storm tracks in a warming climate.

In this thesis, $21^{\text {st }}$ century changes in the annual variance of the MSLP field were 
examined. From those results, potential changes in storm activity are inferred. Examining annual variance was the preferred method because of an interest in the climatological changes that may be taking place in the MSLP of the NPO under different forcing scenarios, and a parallel interest to investigate model-to-model variability. As Bengtsson et al. (2006) and Hoskins and Hodges (2002) explain, using the annual variance of the MSLP field produces a broad picture of how the field might change in a warming climate.

The methods and results are detailed in Sections 2 and 3. The mean changes in the annual variance of MSLP are quantified and summarized from the two multimodel groups introduced in Section1, in Section 3a. In Section 3b, the attributes of the changes calculated from the annual variance study are analyzed and discussed. In Section 3c, an explanation of model equilibrium climate sensitivity values is provided. In addition, the results of a correlation study between model sensitivity and simulated changes in annual variances from each scenario are given. In Section 4, some possible implications from the results are discussed, as are future research opportunities.

\section{Methods}

Table 1 lists the models used in this study. In several studies performed by other researchers, these models have been verified by comparison studies using $20^{\text {th }}$ century observations (e.g., Lambert and Fyfe, 2006), and were extensively used in the IPCC AR4 published in 2007 (see Randall et al. 2007). When available from each model, monthly MSLP values simulated from three emission scenarios were used in this study to investigate the $21^{\text {st }}$ century changes in the annual variance of the NPO. The monthly MSLP da- 
ta used in this study were obtained from the archives of the Program for Climate Model Diagnosis and Intercomparison. The three $\mathrm{CO}_{2}$ emission scenarios considered are A2 (836 ppm of $\mathrm{CO}_{2}$ by 2100), A1B (703 ppm of $\mathrm{CO}_{2}$ by 2100), and $\mathrm{B} 1$ (540 ppm of $\mathrm{CO}_{2}$ by 2100).

At each gridpoint in a model, the annual variance $(A V)$ was calculated from 12 monthly MSLP values, $N$, using Eq. 1 .

$$
A V_{i, j}^{y}=\frac{1}{N-1} \sum_{k=0}^{N-1}\left(x_{k}-\bar{x}\right)^{2},
$$

The superscript, $y$, indicates the year and the subscripts, $i$ and $j$, indicate the gridpoint. The subscript, $k$, indicates the individual monthly MSLP value and $N$, is the number of months per year. The application of Eq. (1) yields 100 annual variance values at each gridpoint and was then repeated for each model and scenario.

From the century of $A V$ values, the climatological change is evaluated by taking 30-year means and calculating a percent difference. A percent difference in the annual variance of the $21^{\text {st }}$ century, $\triangle A V_{21 C}$, is calculated by subtracting the average of the first $30 \mathrm{AV}$ values from the average of the last $30 \mathrm{AV}$ values, and then dividing by the average of the first $30 A V$ values. The resultant value is then multiplied by 100 . Subscripts on the right-hand side of Eq. (2) denote the first (F30) and last (L30) 30 years of the $21^{\text {st }}$ century.

$$
\Delta A V_{21 C}=\frac{\overline{A V_{L 30}}-\overline{A V_{F 30}}}{\overline{A V_{F 30}}} * 100,
$$

Using Eq. (2), $\Delta A V_{21 C}$ is calculated at each gridpoint and the application was repeated for each model and scenario. A negative (positive) value indicates a climatological decrease 
(increase) in the annual variance of the SLP.

\section{Results}

\section{a. Two multimodel summaries of the mean change in annual variance}

Figures 1-3 are the contour plots of globally calculated $\triangle A V_{2 I C}$ for each emission scenario for select models. The model data plotted in Figs. 1-3 provides a sample of the extensive variability that is seen between the models involved in this study. The two panels in each figure display the model that exhibited the maximum positive (top), and maximum negative (bottom), change in $\triangle A V_{2 I C}$ values that were calculated from a spatial-average taken over the area defined by $50^{\circ}-70^{\circ} \mathrm{N}$ and $165^{\circ} \mathrm{E}-160^{\circ} \mathrm{W}$ (hereafter referred to as Region 1 and indicated with a red box on each panel). Region 1 is chosen as an example of the extensive model-to-model variability seen in a region of high midlatitude cyclonic activity in the NPO.

Figure 1 is an example of the variability between models with the A2 scenario. In Region 1, HADGEM1 has the maximum increase in $\triangle A V_{2 l C}(18.8 \%)$ and GISS has the maximum decrease in $\triangle A V_{21 C}(-23.5 \%)$. Figure 2 is the same as Fig. 1, except for the A1B scenario. In the A1B scenario, HADGEM1 has the maximum increase in $\triangle A V_{2 l C}$ (36.6\%) and GISSEH has the maximum decrease in $\triangle A V_{2 I C}(-4.4 \%)$. In Fig. 3, the same as Fig. 1 except for the B1 scenario, BCCR has the maximum increase in $\triangle A V_{21 C}(24 \%)$, and IAP has the maximum decrease in $\triangle A V_{21 C}(-7 \%)$. From these figures, large modelto-model variability on the future changes of the MSLP field is evident. 


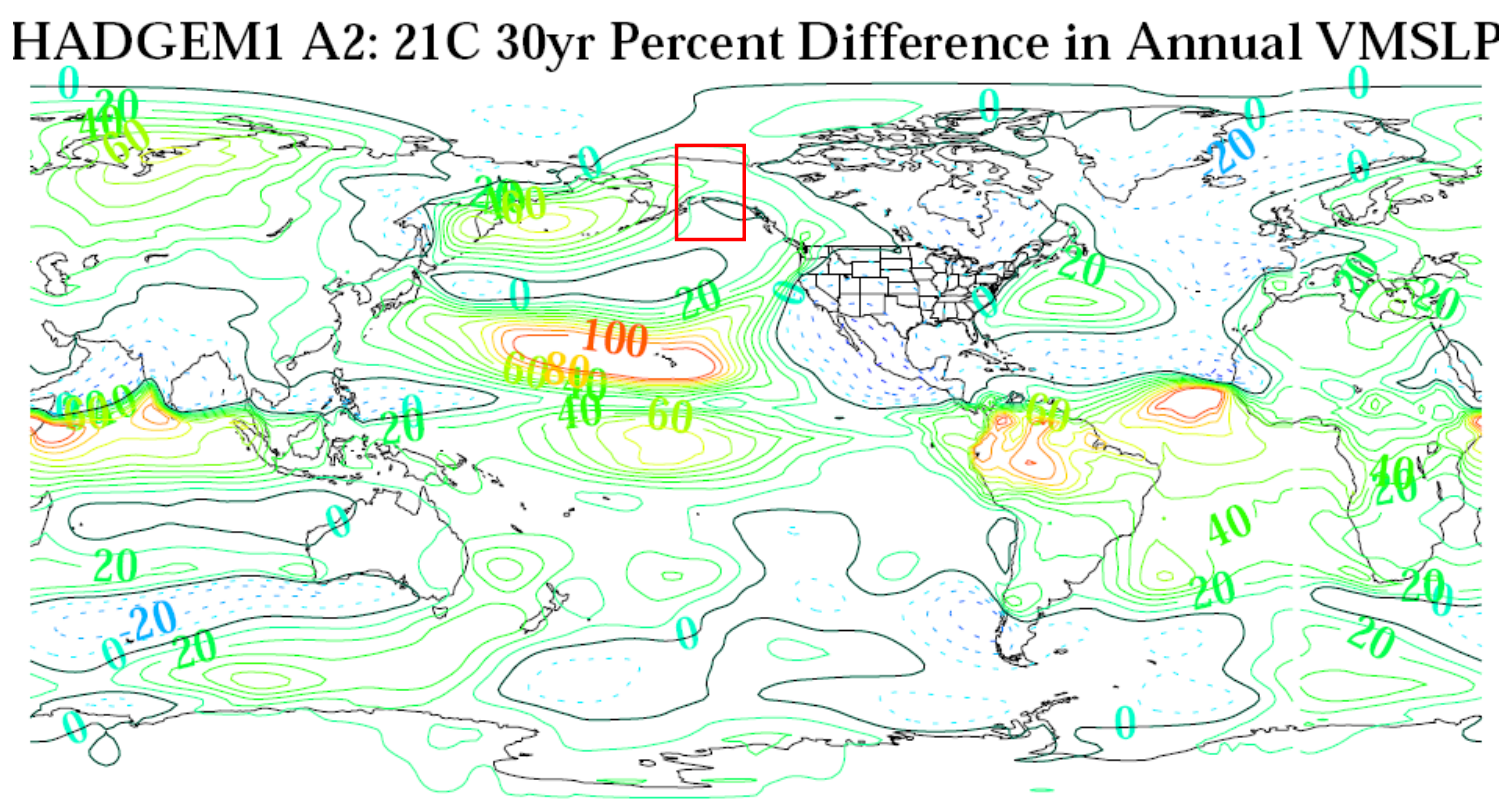

\section{GISS A2: 21C 30yr Percent Difference in Annual VMSLP}

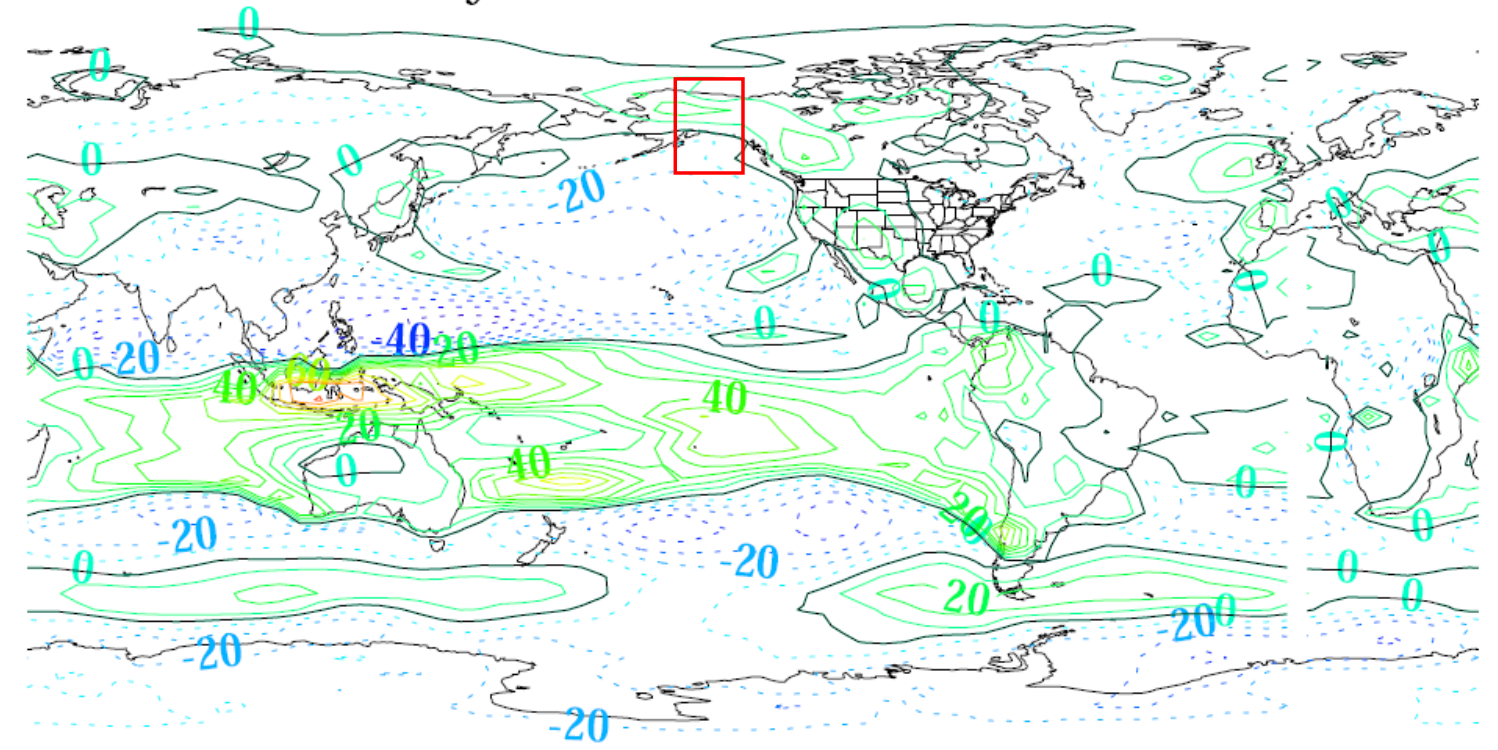

Fig. 1. From the A2 scenario, the top (bottom) panel indicates the model with the maximum increase (maximum decrease) in spatially-averaged $\triangle A V_{21 C}$ calculated within the red box (Region 1). Solid (dashed) lines indicate positive (negative) change in variance. Contour increment is $10 \%$. The zero-change contour is indicated in black. 
HADGEM1 A1B: 21C 30yr Percent Difference in Annual VMSLF

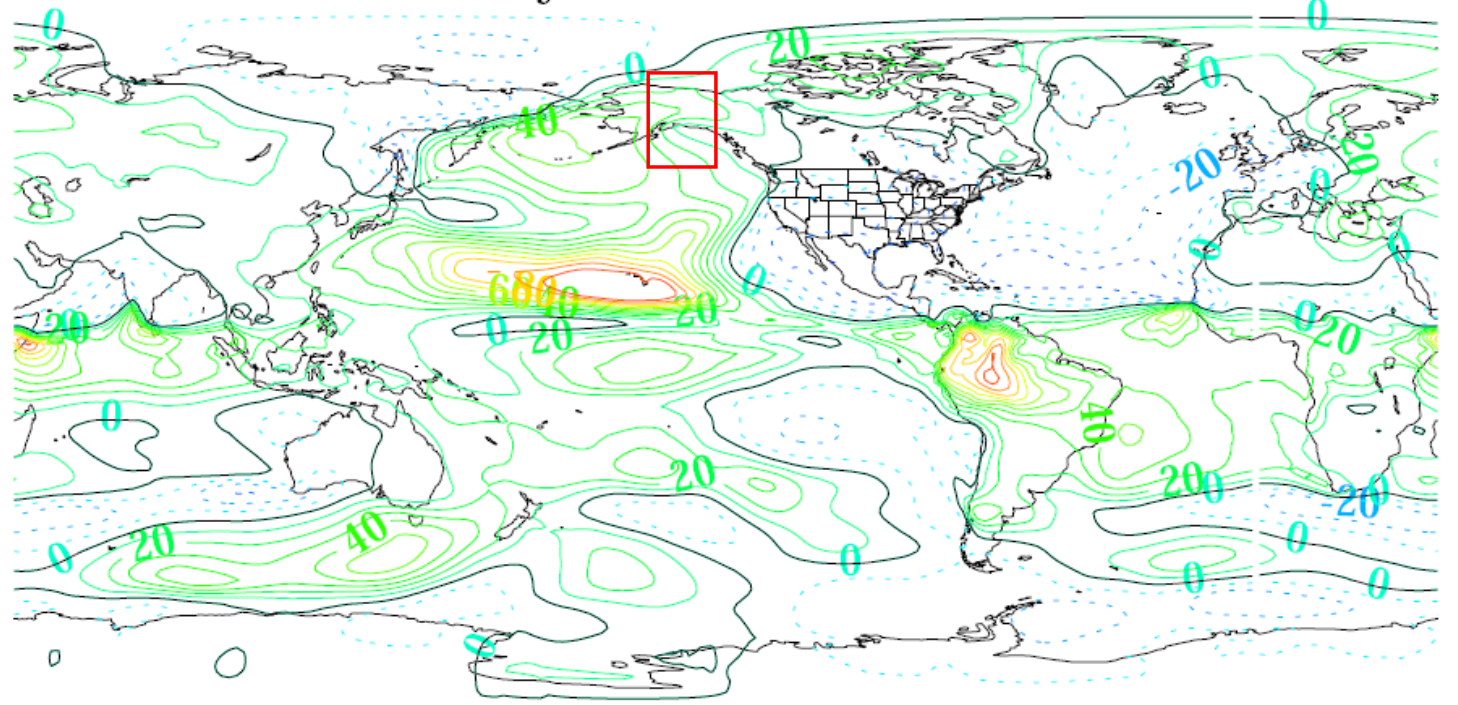

\section{GISSEH A1B: 21C 30yr Percent Difference in Annual VMSLP}

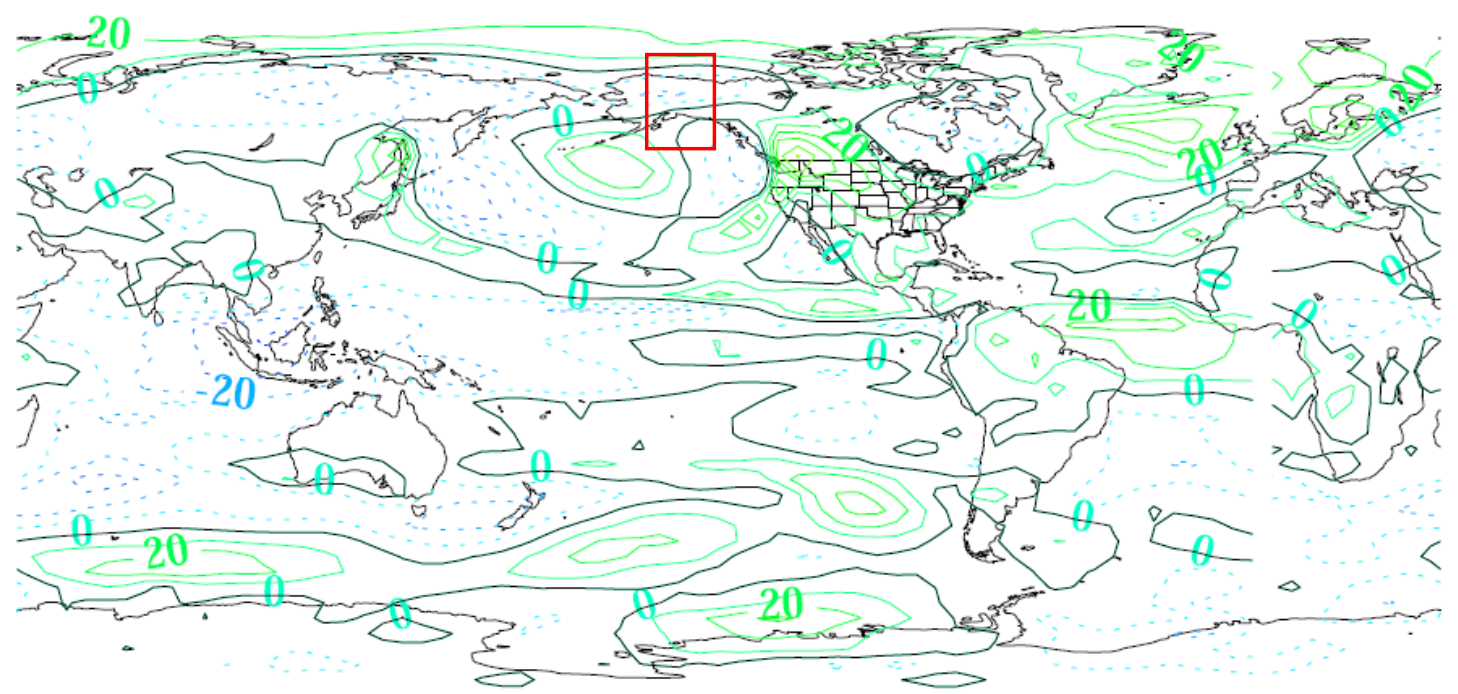

Fig. 2. Same as in Fig. 1 except for A1B scenario. 


\section{BCCR B1: 21C 30yr Percent Difference in Annual VMSLP}
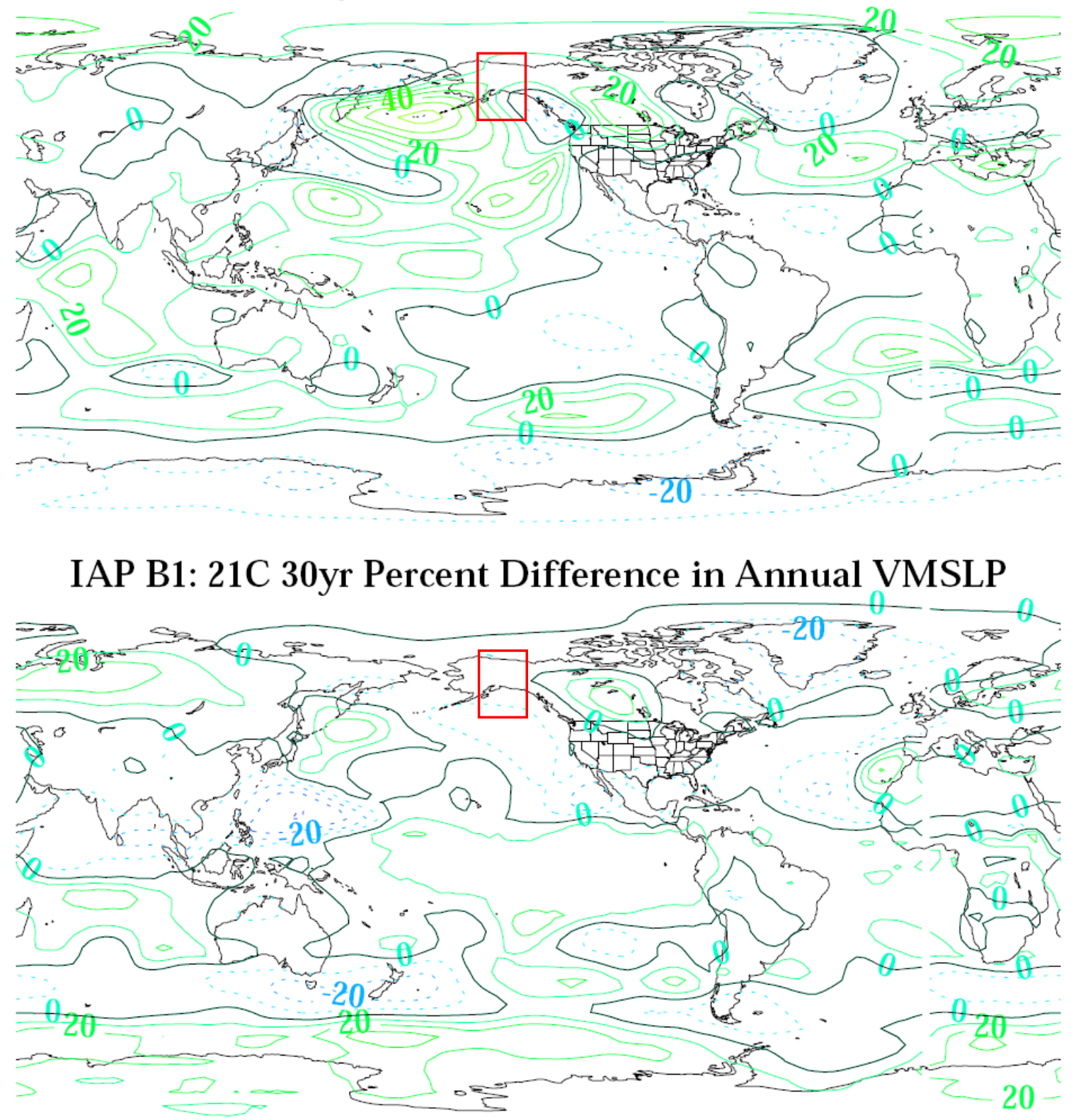

Fig. 3. Same as in Fig. 1 except for B1 scenario. 
Multimodel means were calculated by averaging the $\triangle A V_{21 C}$ values given by individual models. These values were calculated within eight separate regions throughout the NPO. These eight regions were chosen to segment the NPO into distinct zones that have similar climatologies and seasonal activity. In each of the eight regions, the multimodel means and standard errors (SEs) of the spatially-averaged $\triangle A V_{2 I C}$ values from each scenario were computed and are provided in Fig. 4. A ratio indicating the number of models with a positive $\triangle A V_{2 I C}$ relative to the total number of models analyzed in that scenario is also provided.

Results from the multimodel group are shown in Fig. 4, and statistically significant values are in bold type. For Regions 1-4 and 6, statistically significant positive increases in the annual variance at the end of the $21^{\text {st }}$ century occur in at least one of the scenarios. Scenario A2 shows positive $\triangle A V_{2 I C}$ in Regions 2 and 4 . It is the only scenario to show statistically significant decreasing variance $(-8 \pm 7.7 \%)$, which occurs in Region 5. Scenario A1B results show positive increases in $\triangle A V_{2 I C}$ for Regions $1,2,3$, and 4 with an average increase of $11.6 \%$. Scenario B1 results indicate that positive increases in the $\triangle A V_{21 C}$ occurs for Regions 1, 2, and 6 .

Due to the agreement between the spatially-averaged values, an additional multimodel mean of the $\triangle A V_{21 C}$ was calculated for a new area, Region 9. Region 9 is a combination of Regions 1, 2, 3, 4, and 6. In each scenario, the Region 9 results indicate robust model agreement that statistically significant positive changes in $\triangle A V_{21 C}$ will occur in that large area that is seasonally dominated by the Aleutian Low. The results showed increases in $21^{\text {st }}$ century annual variance on the order of $5.8 \pm 2.5 \%$ (A2), $9.3 \pm 2.4 \%$ 
(A1B), and $5.1 \pm 2 \%$ (B1).

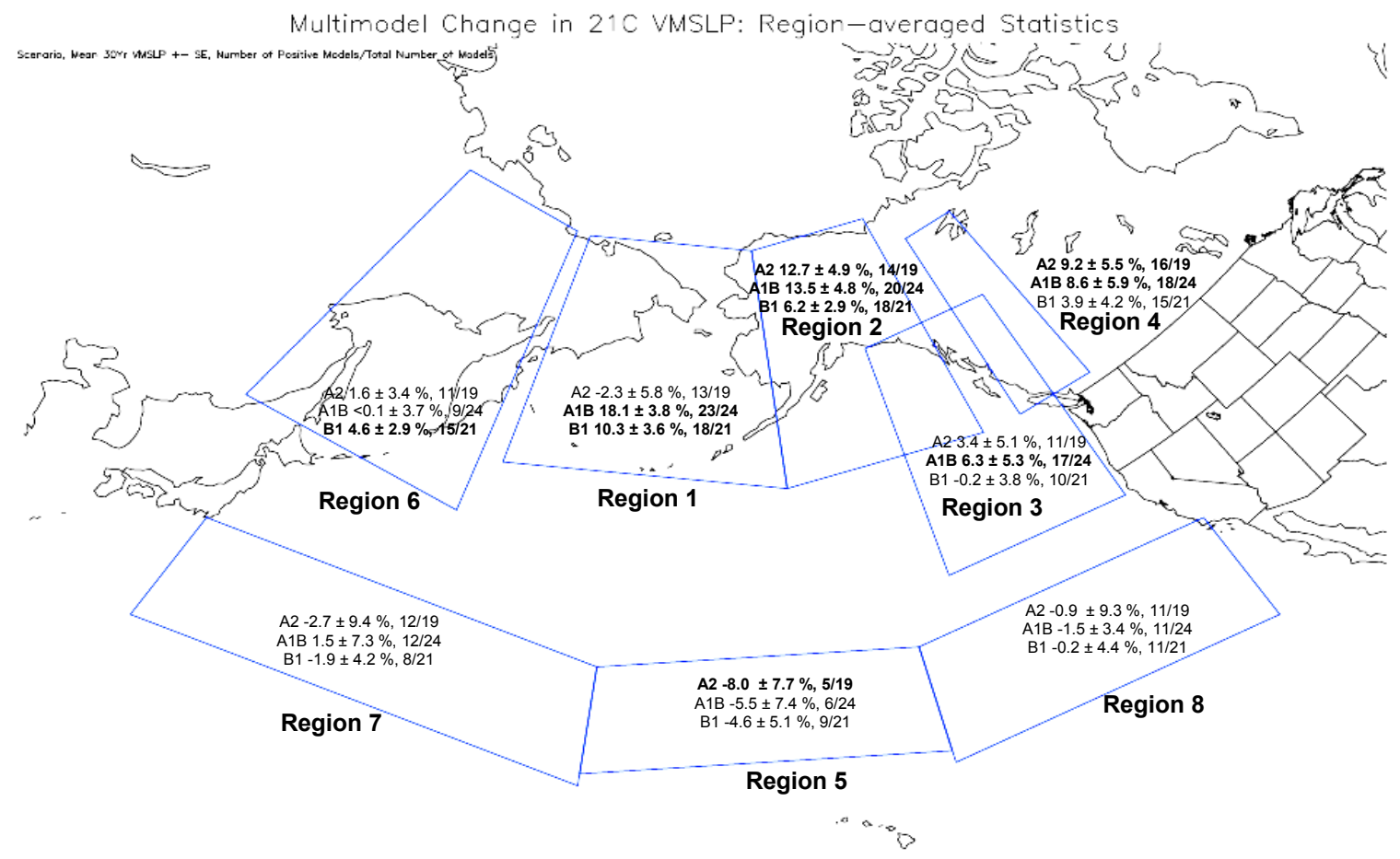

Fig. 4. Map of eight regions in the NPO that were used for the multimodel group statistical analyses discussed in Section 3a. Listed in each region is the multimodel mean change in $\triangle A V_{2 I C}$ and $\mathrm{SE}$ calculated from each scenario. Following that entry is a ratio indicating the number of models with positive values relative to the total number of models used for that scenario. Bold entries indicate statistically significant results at the $95 \%$ CL.

A standard $t$-test was performed to determine if the multimodel group changes, calculated from each scenario, were statistically different from one scenario to another. The results indicate that in Region 9, the multimodel mean change from the A1B scenario is significantly different from either the A2 or B1 scenario changes. However, the multimodel mean changes given by the A2 and B1 scenarios are not statistically significantly different from each other.

This finding indicates that the magnitude of change in $\triangle A V_{21 C}$ does not linearly increase with increased $\mathrm{CO}_{2}$ forcing. By comparing the $\mathrm{A} 2$ and $\mathrm{A} 1 \mathrm{~B}$ results, it appears 
that with the higher forcing scenario (A2), the annual variability of MSLP decreases. This result runs counter to the findings of LF06 and P07, who reported in their studies that the magnitude of change in storm tracks was dependent on the forcing. It is not clear if the reduced $\triangle A V_{2 I C}$ in the $\mathrm{A} 2$ scenarios indicates that seasonal variability will return to prior levels by the end of the $21^{\text {st }}$ century, or if it indicates future changes in the fundamental processes of storm development in the middle-latitudes.

In Fig. 5, the results from the select-multimodel group are provided. However, before the results in Fig. 5 are discussed, a brief passage follows in which the rationale for using a select group of models is provided and as well as the selection criteria. The rationale for singling out a subset of models to examine as a separate multimodel group was to explore the possibility that some models may be better than others at resolving atmospheric processes. A group comprised of these superior performers would conceivably provide a more skillful prediction of the future climate in the NPO. Moreover, comparing the results between the two multimodel groups would demonstrate the sensitivity of the study to the models chosen, and indicate the robustness of the results.

After performing a literature review on the subject of model performance, the index crafted by Reichler and Kim (2008) was used to select the members of the selectmultimodel group. Reichler and Kim (2008) developed their metric to objectively quantify the degree of agreement between model simulations of the $20^{\text {th }}$ century and $20^{\text {th }}$ century observations. Using a wide range of variables, they derived an index that ranked the models from poor-to-best performance in simulating $20^{\text {th }}$ century observations. Models that ranked at least average or better became the members of the select-multimodel 
group. Bold entries in Table 1 identify the members of the select-multimodel group used for the studies performed in this thesis.

The select-multimodel mean changes in $\triangle A V_{2 I C}$ and SEs are shown in Fig. 5. The ratios indicate the total number of models with positive $\triangle A V_{2 I C}$ values relative to the total number of models available for that scenario. The number of statistically significant values (bold type) is fewer compared to the multimodel study. However, the agreement between scenarios is more robust in two broad regions. In Regions 1 and 2, the A2, A1B, and $\mathrm{B} 1$ results are all statistically significant, and show positive increases in $\triangle A V_{2 l C}$. As in the multimodel analyses, the magnitude of change appears to reach a maximum with the A1B scenario, reinforcing earlier results that the magnitude of change does not follow the forcing.

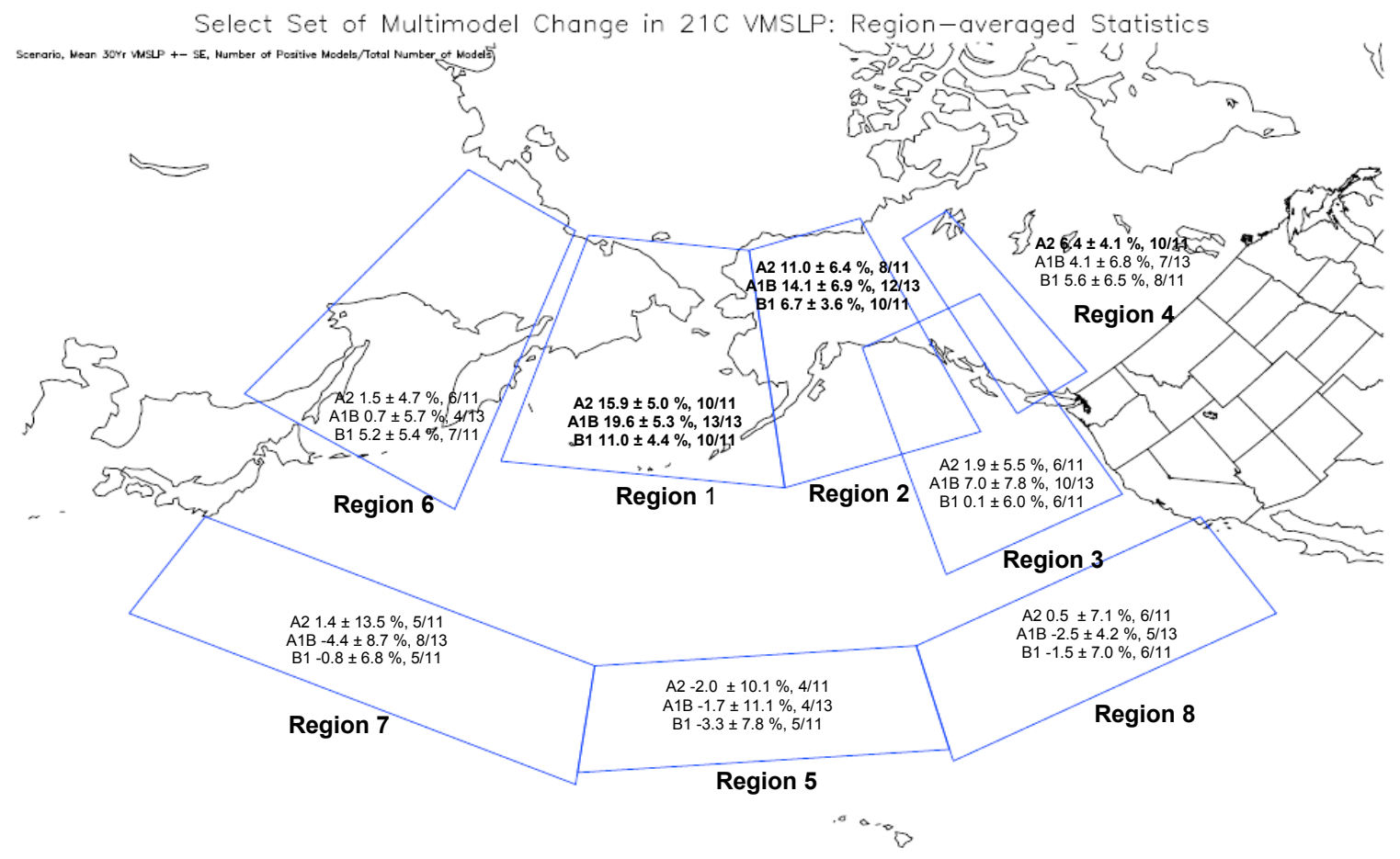

Fig. 5. Same as in Fig. 4 except for the select-multimodel group. 


\section{b. Characteristics of annual variability and interpretation of 3 a findings}

Calculating the annual variability of monthly MSLP helps to determine the range of seasonal activity an area is likely to experience in a given year. The NPO is a vast area, with regions that seasonally experience frequent baroclinic disturbances, and regions that experience frequent, semi-permanent high-pressure systems. Examining longterm variability of the MSLP field helps to identify changes to seasonally active zones. Although the $\triangle A V_{2 l C}$ calculation indentifies a climatological change occurring in a region, it does not characterize the nature of the change in the pressure field.

To characterize the nature of the changes given by the $\Delta A V_{2 I C}$ calculations in the preceding subsection, several statistical studies were performed on the multimodel average of monthly MSLP data. With the A1B scenario, the multimodel mean revealed a statistically significant, decreasing trend $\left(-0.01 \mathrm{hPa} \mathrm{yr}^{-1}\right.$, Fig. 6) in the annually averaged, monthly MSLP values for Region 9. Figure 7 shows a statistically significant, decreasing trend $\left(-0.02 \mathrm{hPa} \mathrm{yr}^{-1}\right)$ in the annual minimum monthly MSLP values of the A1B scenario for Region 9. An analysis of maximum monthly MSLP values showed no statistically significant trends over the century.

The number of monthly mean values that were less than or equal to a threshold of $1005 \mathrm{hPa}$ were also studied. This threshold of $1005 \mathrm{hPa}$ is known as the Aleutian Low Index, and identifies pressure values associated with the Aleutian Low (see Rodionov et al. 2004). In the first 30 winters (in this study, winter is defined by November to March) of the A1B $21^{\text {st }}$ century, there were 17 monthly MSLP values $\leq 1005 \mathrm{hPa}$. That number increased to 24 in the last 30 winters of the century. Comparing the number of pressure 
values $\leq 1005 \mathrm{hPa}$ suggests an increase in the frequency of months with a lower monthly average in future SLP values. For the A1B scenario, this indicates that positive $\triangle A V_{21 C}$ values imply increased monthly low-pressure activity as opposed to increased monthly high-pressure activity in winter. The increased monthly low-pressure activity will result from deeper than average low-pressure systems and/or increases in the frequency of monthly low-pressure systems during winter in the NPO.

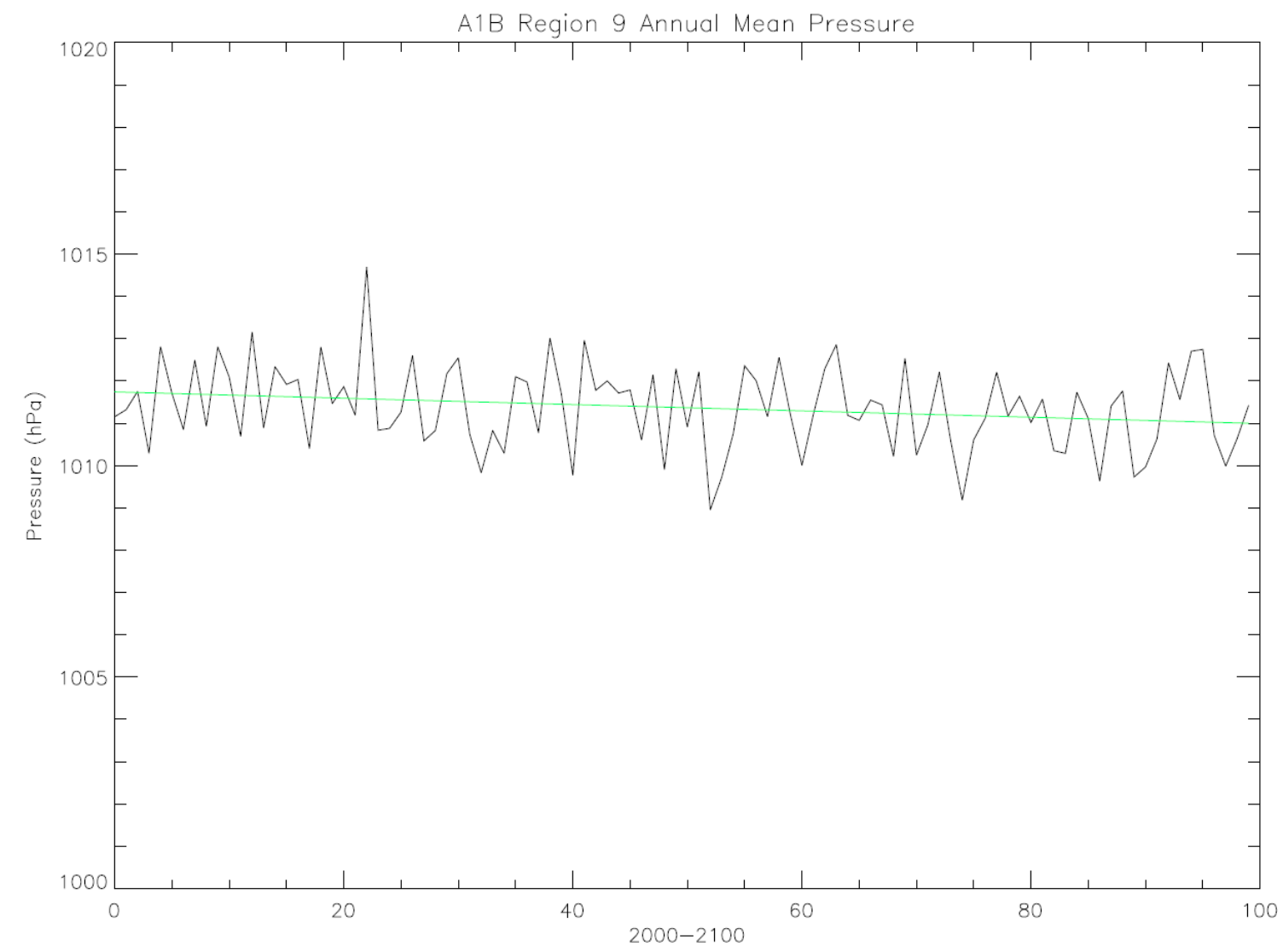

Fig. 6. For the A1B scenario, the Region 9 area-average of the multimodel-mean, annually-averaged MSLP. The decreasing trend is statistically significant $\left(-0.01 \mathrm{hPa} \mathrm{yr}^{-1}\right)$.

Figure 8 indicates a statistically significant decreasing trend $\left(-0.01 \mathrm{hPa} \mathrm{yr}^{-1}\right)$ in the annually-averaged monthly MSLP values calculated from the B1 scenario in Region 9. In the $\mathrm{B} 1$ emission scenario, a count of MSLP values $\leq 1005 \mathrm{hPa}$ also indicates a future 
increase in the frequency of monthly low-pressure values.

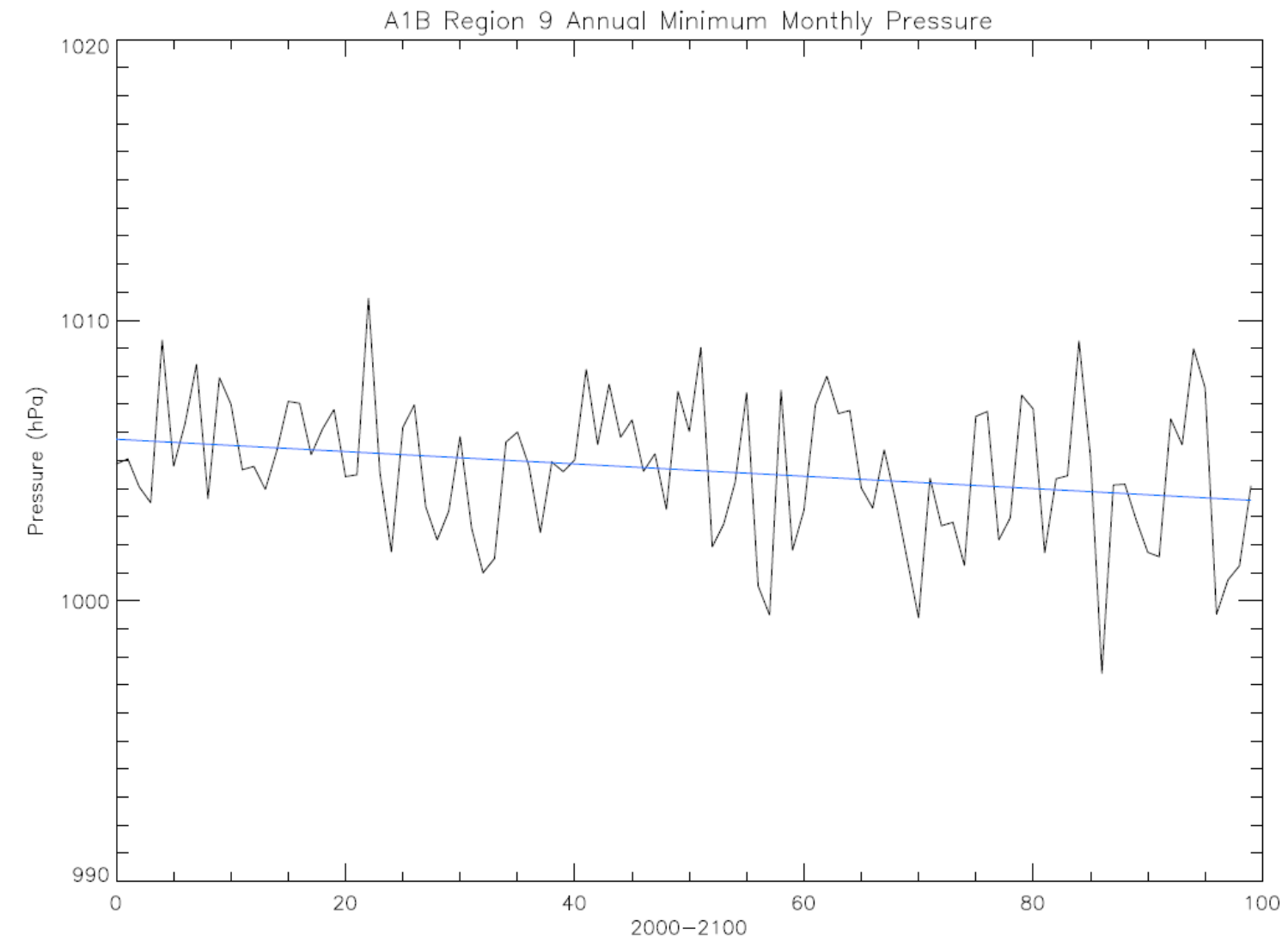

Fig. 7. For the multimodel-mean of the A1B scenario. Plot indicates the Region 9average of minimum monthly SLP pressure values for each year. The decreasing trend is statistically significant $\left(-0.02 \mathrm{hPa} \mathrm{yr}^{-1}\right)$.

In the first 30 winters of the $\mathrm{B} 1$ century, there were 44 monthly MSLP values $\leq$ $1005 \mathrm{hPa}$, and 55 in the last 30 winters. With the A2 scenario, a count of low-pressure values $(\leq 1005 \mathrm{hPa})$ also returned an increase from 16 to 22 monthly mean SLP values between the first 30 and last 30 winters. These results consistently indicate deeper than average monthly lows and/or increases in the monthly frequency of low-pressure activity during winter can be expected for the future in the NPO.

Using these statistical analyses, the nature of $\triangle A V_{2 I C}$ values discussed in Section 
3a can now be understood. Positive $\triangle A V_{2 I C}$ values can be attributed to increases in winter low-pressure activity. Conversely, a negative $\triangle A V_{2 I C}$ value indicates a reduction in the winter low-pressure activity. The statistical analyses in Section 3a showed robust model agreement that the annual variance in the MSLP field will increase for several areas of the NPO. These results indicate that the climate of those regions is shifting toward deeper and/or more frequent low-pressure activity during the winter months. In addition, the results from Section 3a combine to suggest that storm activity may intensify and/or increase in frequency as forcing increases to B1-levels (540 ppm).

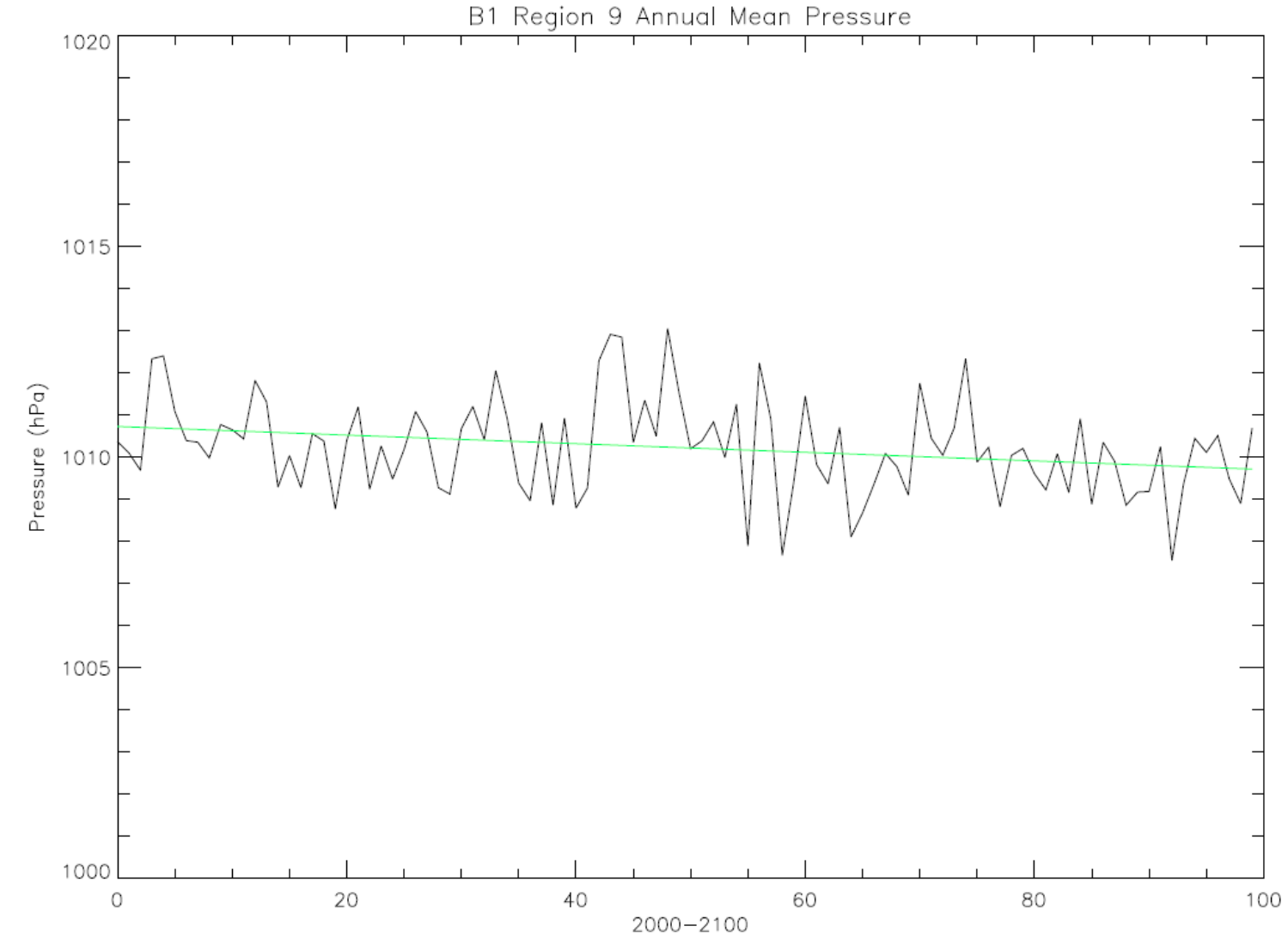

Fig. 8. From the multimodel-mean of the B1 scenario, the annually averaged MSLP for Region 9 and trend line. The decreasing trend is statistically significant $\left(-0.01 \mathrm{hPa} \mathrm{yr}^{-1}\right)$.

As A1B-levels are reached (704 ppm), storm activity may slightly decrease in frequency, 
but storm intensity will increase and low-pressure systems will become notably deeper. At A2-levels (836 ppm), the meridional temperature gradient may appreciably decrease and markedly reduce cyclogenesis in the middle latitudes. These results indicate that the magnitude of change in storm activity does not follow the forcing.

\section{c. Correlation between the magnitudes of change in $\triangle A V_{21 C}$ and ECS values}

Model equilibrium climate sensitivity (ECS) values are derived from the equilibrium temperature $\left({ }^{\circ} \mathrm{C}\right)$ reached after a 100 year simulation in which the models were forced with $540 \mathrm{ppm}$ of $\mathrm{CO}_{2}$. The ECS value helps to rank a model's sensitivity to $\mathrm{CO}_{2}$ forcing. Low values, such as those shared by INMCM and NCAR at $2.1^{\circ} \mathrm{C}$; indicate models which exhibit low sensitivity to $\mathrm{CO}_{2}$ forcing. HADGEM1 and IPSL both share the $4.4^{\circ} \mathrm{C}$ value which indicates those models show comparably higher sensitivities to $\mathrm{CO}_{2}$ forcing. ECS values were the chosen for the correlation study that follows because their availability maximized the number of models that could be included. ECS values were published in the 2007 IPCC AR4 report, and the pertinent information is reproduced in Table 1 (Randall et al., 2007).

In this portion of this thesis, ECS values are used to conduct a correlation study to determine if the magnitude of change in $\triangle A V_{2 I C}$ can be predicted by a model's sensitivity to $\mathrm{CO}_{2}$ forcing. In other words, does a model with a high ECS value return a stronger change in annual variance? To objectively examine the domain of the NPO, numerous randomly designated areas were chosen. In each area, the spatially-averaged $\triangle A V_{2 I C}$ values from each model were regressed with their respective ECS values. This procedure was done separately for the multimodel group and the select-multimodel group. Figures 
9 and 10 are included to demonstrate the nature of a positive correlation.

Figure 9 typifies a random region in which a positive correlation was found. In this example, the positively correlated region is designated by an orange box. This demonstrates where the linear regression calculated between the select-multimodel group and respective ECS values in the A2 emission scenario returned a positive relationship between the magnitude of change in $\triangle A V_{21 C}$ and model sensitivity. Figure 10 is the accompanying linear regression scatterplot for the region shown in Fig. 9. The ECS values in the legend are for the members of the select-multimodel group. A strong positive relationship $(r=0.8)$ between the degree of change in the $\triangle A V_{21 C}$ and model sensitivity is evident.

Figure 11 displays the results from the multimodel group correlation study. Regions with positive (negative) correlations that are statistically significant, at the $95 \% \mathrm{CL}$ or better, are indicated with orange (green) boxes. A dense grouping of positively correlated areas is found in the eastern part of the NPO from each scenario. In addition, a small region of negatively correlated areas is found in the lower-half of the eastern NPO (A1B scenario). A discussion of the results from each scenario in Fig. 11 follows. Scenario A2 (top right panel) shows positively correlated regions from eastern Siberia to the middle portions of Alaska and from the Bering Sea to Fort Barrow, Alaska. The A2 scenario also indicates positively correlated regions exist off the west coast of the U.S. The results indicate that greater magnitudes of change in $\triangle A V_{21 C}$ are correlated to higher ECS values. No negatively correlated regions exist in the A2 scenario (top left panel). The regions of positive correlation in the A1B case (middle right panel) is densely 
located over the Bering Strait, eastern half of the Bering Sea, all of Alaska, the Canadian Rocky Mountains, and the Gulf of Alaska. A1B is the only scenario with negatively correlated regions (middle left panel) located off the west coast of the U.S. and further south. The B1 scenario exhibits a combination of the A2 and A1B scenarios with an extension down the west coast of the U.S. to the Tropic of Cancer (bottom right panel). The bottom left panel shows no negatively correlated regions.

A2 Select Multimodel Region 266: Positive Correlation between ECS and VMSLP
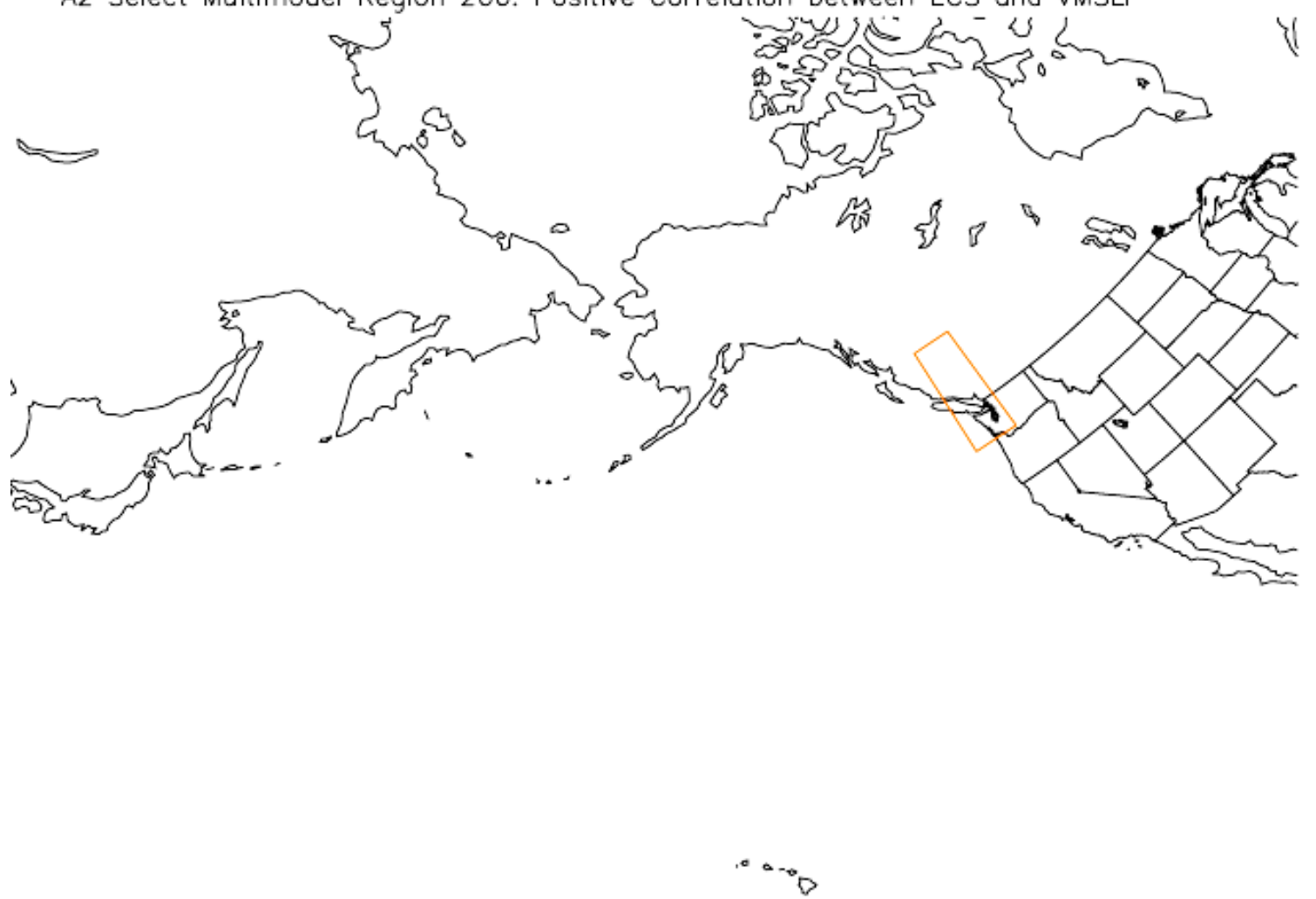

Fig. 9. An example region (orange box) from the select-multimodel correlation study of the A2 scenario. The orange box indicates where a positive correlation between $21^{\text {st }}$ century increases in annual variance and model ECS values was found.

The results for the select-multimodel group are in Fig. 12. All scenarios indicate positively correlated regions along the eastern portions of the NPO. For scenario A2 (top right panel), increases are indicated for the lower half of the NPO, Canadian Rocky 
Mountains, eastern part of the Gulf of Alaska, and southward to the Tropic of Cancer; there are no negatively correlated regions in the A2 case. In A1B (middle right panel),

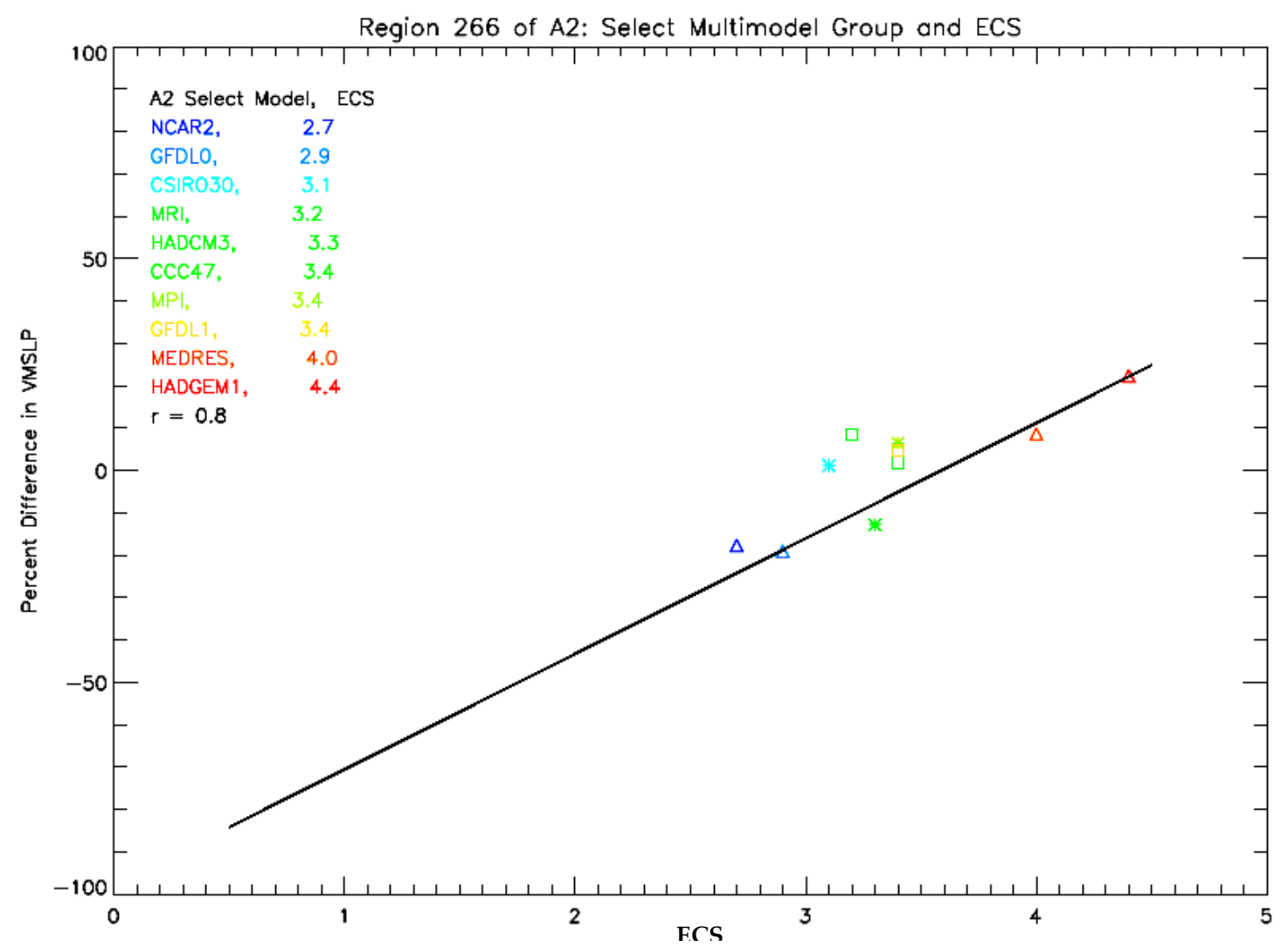

Fig. 10. A linear regression plot for the area shown in Fig. 9. Model ECS values are on the $\mathrm{x}$-axis and the percent difference in the $21^{\text {st }}$ century change in annual variance $\left(\triangle A V_{21 C}\right)$ is on the $\mathrm{y}$-axis.

areas are grouped over the Canadian Rocky Mountains, eastern part of the Gulf of Alaska, and extending southward to the Tropic of Cancer. The B1 results (bottom right panel) resemble the A1B coverage.

Negatively correlated regions result from the A1B and B1 scenarios (middle left and bottom left panels, respectively), and populate the western half of the NPO. A1B exhibits many more negatively correlated areas in the western half of the NPO, and B1 exhibits negatively correlated areas extending from northern Japan to the Sea of Okhotsk. 
The areas with negative correlations indicate a statistically significant relationship that describes how models with higher ECS values simulate less strong changes in the $\triangle A V_{21 C}$. Similarly, models with lower ECS values simulate stronger changes in the annual variance of the area.
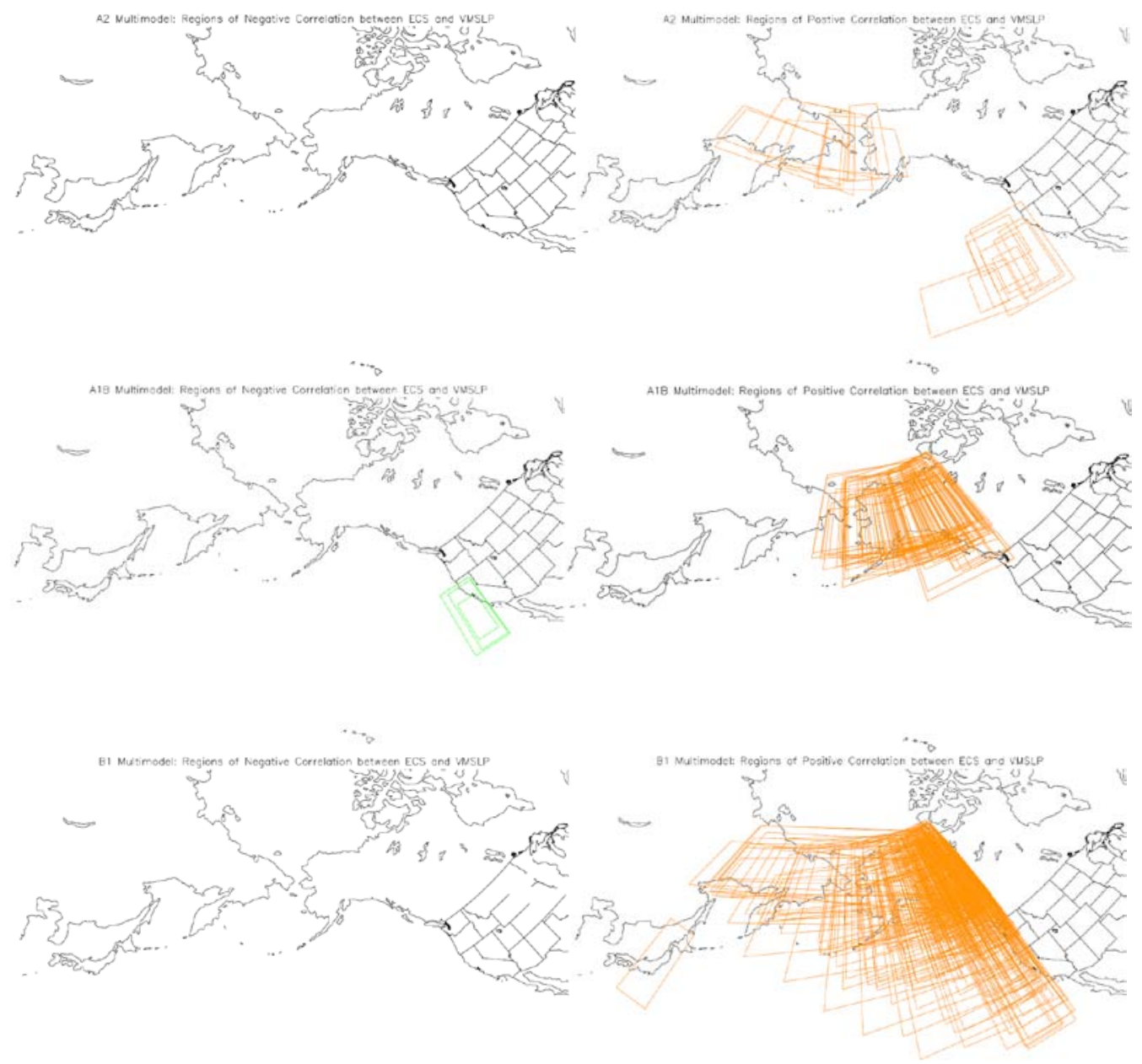

Fig. 11. Results from the linear regression analysis of the multimodel group study where correlations were found. Regions that are positively (orange boxes) and negatively (green boxes) correlated indicate a relationship was found between the magnitude of change in annual variance predicted by the models and the model ECS values. Results are from the A2 (top panels), A1B (middle panels), and B1 (bottom panels) scenarios. 

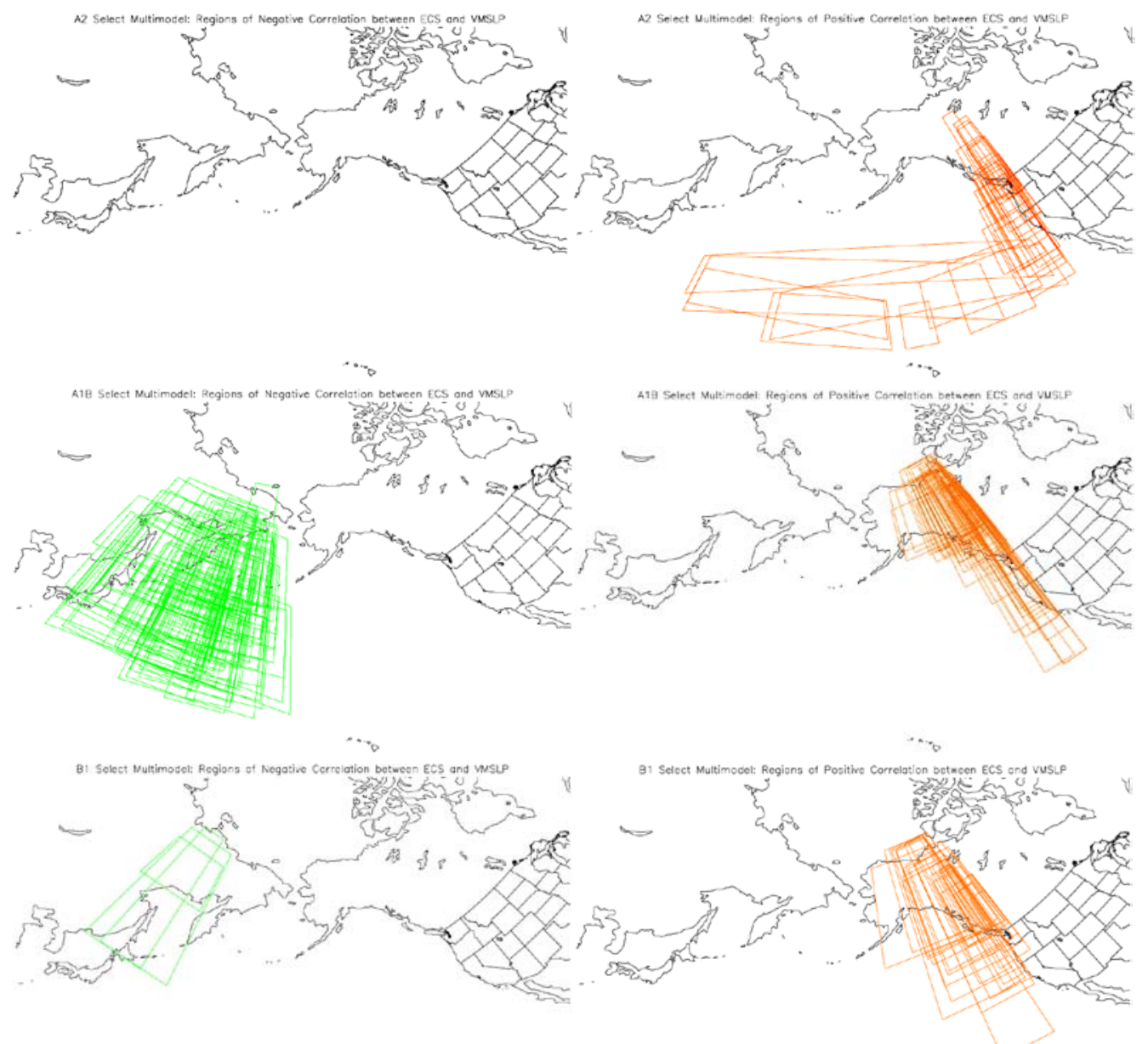

Fig. 12. Same as in Fig. 11 except for the select-multimodel group.

In summary, the results from the multimodel and select-multimodel groups indicate that in the eastern half of the NPO, positive correlations exist between the magnitude of individual model $\triangle A V_{2 I C}$ values and model sensitivity to $\mathrm{CO}_{2}$ forcing. These results are robust between scenarios. The results suggest that in those areas, a model with a higher ECS value will simulate a greater change in the future annual variance of MSLP. In addition, negatively correlated areas were found in the western half of the NPO and lower-half of the eastern NPO. Negative correlations indicate that models with higher 
ECS values exhibit less intense changes in $\triangle A V_{21 C}$.

Both multimodel groups give similar results in similar areas indicating that the nature of those correlations is a robust feature for the eastern portions of the NPO and warrants further investigation. Why this correlation does not exist in all parts of the NPO is unclear. Why negative correlations appear only in the A1B (and B1) scenario is also unclear. Both of these questions present opportunities for further study.

\section{Discussion and Future Work}

Statistical analyses of the climtatological changes in the annual variance of MSLP over the NPO were conducted for the A2, A1B, and B1 scenarios using two multimodel groups. The metric employed for the analyses was the change between the first and last, 30-year averaged, annual variance values of monthly MSLP $\left(\triangle A V_{21 C}\right)$. Due to the inherent differences between GCMs, parallel investigations took place using two different multimodel groups. From the two multimodel groups, the changes in the $\triangle A V_{21 C}$ simulated by the models were quantified and summarized, model variability was investigated and discussed, and a link between model sensitivity and model output was also explored.

The results from the three emission scenarios used in this thesis combine to indicate robust agreement that annual variance in MSLP will increase by the end of the $21^{\text {st }}$ century for the Gulf of Alaska, Canadian Rocky Mountains, the Bering Sea/Strait, and the west coast of the U.S. These results suggest these regions will experience increased wintertime low-pressure activity by the end of the $21^{\text {st }}$ century. This increased low-pressure activity may be from deeper than average lows and/or increases in the frequency of mon- 
thly low-pressure activity in the winter.

The statistical analyses suggested a relationship between the magnitude of change in forcing and the change in storm activity but not to the same degree as discussed in LF06 and P07. From both multimodel groups, the statistical summary of mean change in $\triangle A V_{21 C}$ revealed that, as forcing increased beyond A1B levels, the mean change did not continue to increase but instead decreased. The change from A2 resembled the order of change seen from the B1 analyses, but this does not mean that the mechanisms associated with the mean variability found in those cases were the same. The physical implications of this finding are suggestive of the long-term effects associated with a decreasing and poleward displacing meridional temperature gradient. However, it is not realistic to expect that the jet stream will perpetually move poleward in response to elevating GHG levels. At the maximum forcing investigated, the degree of change in $\triangle A V_{21 C}$ was less than for A1B in both multimodel group studies. This may have indicated that under A2 forcing levels, low-pressure activity reduces and resembles storm activity seen from lower emission scenarios. Alternatively, the nature of storm dynamics could change for the middle latitudes in a way that resembles storm processes found in the tropics. In either case, the result was indicative of an upper limit to the poleward displacement of the jet stream and the frequency of baroclinic disturbances.

The results from this thesis lead to additional speculations about the future responses of seasonal, low-pressure activity over the NPO in highly perturbed GHG forcing scenarios. As GHG forcing progresses through B1 and A1B levels, baroclinic activity may continue to strengthen along with the poleward-displacing (maximum) meridional 
temperature gradient (BHR06; Y05). As the poles continue to warm, it is plausible that an appreciably decreased meridional temperature gradient would cause the jet stream to exhibit predominately zonal flow. To aid in the interpretation of these results, examining paleoclimate records or simulating extreme forcing conditions with high pollutant levels may help to understand changes to storm processes.

From the correlation studies performed on both the multimodel and selectmultimodel groups, areas of positive correlation were found in the eastern portions of the NPO. These robust results indicate that, in those regions, the magnitude of change in $\triangle A V_{2 I C}$ simulated by the models can be predicted by the model's sensitivity to $\mathrm{CO}_{2}$ forcing. Positively correlated areas were found in Alaska, the Gulf of Alaska, the Canadian Rocky Mountains, and the west coast of the U.S. Negative correlations were found in the select-multimodel group, in the west-central portions of the NPO.

Future work could explore the fragmented nature of the correlated areas by performing the calculations for larger portions of the globe and looking for spatial trends. Another approach could investigate connections between the spatial use of certain subgrid parameterizations and positively (or negatively) correlated areas. In addition, the metric of $\triangle A V_{2 I C}$ used in this thesis could be applied to different multimodel groups that are selected based on inherent parameterizations or on the choice to select or neglect models with the lowest or highest sensitivities. Finally, performing the analyses developed in this thesis on other areas where storm track activity is expected to change, for example, the North Atlantic Ocean and portions of the Southern Ocean, would provide valuable feedback regarding the robustness of the analyses used in this thesis. 


\section{REFERENCES}

Archer, C. L., and K. Caldeira, 2008: Historical trends in the jet streams. Geophys. Res. Lett., 35, L08803, doi:10.1029/2008GL033614.

Bengtsson, L., K. I. Hodges, and E. Roeckner, 2006: Storm tracks and climate change. J. Clim., 19, 3518-3543.

Broccoli, A., and S. Manabe, 1990: Can existing climate models be used to study anthropogenic changes in tropical cyclone climate? Geophys. Res. Lett., 17, 19171920.

Emanuel, K., 2006: Climate and tropical cyclone activity: A new model downscaling approach. J. Clim., 19, 4797-4802.

Greeves, C. Z., V. D. Pope, R. A. Stratton, and G. M. Martin, 2007: Representation of Northern Hemisphere winter storm tracks in climate models. Clim. Dyn., 28, 683702.

Harnik, N., and E. K. M. Chiang, 2002: Storm track variations as seen in radiosonde observations and reanalysis data. J. Clim., 16, 480-495.

Hodges, K. I., 1993: A general method for tracking analysis and its application to meteorological data. Mon. Wea. Rev., 122, 2573-2586.

, 1995: Feature tracking on the unit sphere. Mon. Wea. Rev., 123, 3458-3465.

, 1998: Adaptive constraints for feature tracking. Mon. Wea. Rev., 127, 13621373.

Hoskins, B. J., and K. I. Hodges, 2002: New Perspectives on the Northern Hemisphere Winter Storm Tracks. J. Atmos. Sci., 59, 1041-1061.

Jiang, J., and W. Perrie, 2007: The impacts of climate change on autumn North Atlantic midlatitude cyclones. J. Clim., 20, 1174-1187.

, 2008: Climate change effects of North Atlantic cyclones: J. Geophys. Res., 113, 09, doi:10.1029/2007jD008749

Jin, E. K., J. L. Kinter III, B. Wang, C. K. Park, I. S. Kang, B. P. Kirtman, J. S. Kug, A. Kumar, J. J. Luo, J. Schemm, J. Shukla, and T. Yamagata, 2008: Current status of ENSO prediction skill in coupled ocean-atmosphere models. Clim. Dyn., 31, 647664. 
Lambert, S. J., and J. C. Fyfe, 2006: Changes in winter cyclone frequencies and strengths simulated in enhanced greenhouse warming experiments: Results from the models participating in the IPCC diagnostic exercise. Clim. Dyn., 26, 713-728.

Lu, J., G. A. Vecchi, and T. Reichler, 2007: Expansion of the Hadley cell under global warming. Geophys. Res. Lett., 34, L06805.

Lu, J., G. Chen, and D. M. W. Frierson, 2008: Response of the zonal mean atmospheric circulation to El Niño versus global warming. J. Clim., 21, 5835-5851

Pinto, J. G., U. Ulbrich, G. C. Leckebusch, T. Spangehl, M. Reyers, and S. Zacharias, 2007: Changes in storm track and cyclone activity in three SRES ensemble experiments with the ECHAM5/MPI-OM1 GCM. Clim. Dyn., 29, 195-210.

Mochizuki, T., and T. Awaji, 2008: Summertime evolution of decadal sea surface temperature anomalies in the midlatitude North Pacific. J. Clim., 21, 1569-1588.

Randall, D. A., R. A. Wood, S. Bony, R. Colman, T. Fichefet, J. Fyfé, V Kattsov, A. Pittman, J. Shukla, J. Srinivasan, R. J. Stouffer, A. Sumi, and K. E. Taylor, 2007: Climate Models and Their Evaluation. Climate Change 2007: The Physical Science Basis. Contribution of Working Group I to the Fourth Assessment Report of the Intergovernmental Panel on Climate Change. Cambridge University Press, Cambridge, United Kingdom and New York, NY USA, 74 pp.

Reichler, T., and J. Kim, 2008: How well do coupled models simulate today's climate? Bull. Amer. Meteor. Soc., 89, 303-309.

Rodionov, S. N., J. E. Overland, and N.A. Bond, 2004: The Aleutian Low and Winter Climatic Conditions in the Bering Sea. Part I: Classification. J. Clim.,18, 160-177.

Roeckner, E., J. M. Oberhuber, A. Bacher, M. Christoph, and I. Kirchner, 1996: ENSO variability and atmospheric response in a global coupled atmosphere-ocean GCM. Clim. Dyn., 12, 737-754.

Rogers, J. C., 1996: North Atlantic storm track variability and its association to the North Atlantic Oscillation and climate variability of Northern Europe. J. Clim., 10, 1635-1647.

Salathé, E. P., 2006: Influences of a shift in North Pacific storm tracks on western North America precipitation under global warming. Geophys. Res. Lett., 33, 19, doi:10.1029/2006GL026882 
Sanderson, B. M., C. Piani, W. J. Ingram, D. A. Stone, and M. R. Allen, 2008: Towards constraining climate sensitivity by linear analysis of feedback patterns in thousands of perturbed-physics GCM simulations. Clim. Dyn., 30, 175-190.

Stowasser, M., Y. Wang, and K. Hamilton, 2006: Tropical cyclone changes in the Western North Pacific in a global warming scenario. J. Clim., 20, 2378-2396.

Teng, H., W. M. Washington, and G. A. Meehl, 2008: Interannual variations and future change of wintertime extratropical cyclone activity over North America in CCSM3. Clim. Dyn., 30, 673-686.

Ulbrich, U., J. G. Pinto, H. Kupfer, G. C. Leckebusch, T. Spangehl, and M. Reyers, 2008: Changing Northern Hemisphere storm tracks in an ensemble of IPCC climate change simulations. J. Clim., 21, 1669-1679.

Yin, J. H., 2005: A consistent poleward shift of the storm tracks in simulations of $21^{\text {st }}$ century climate. Geophys. Res. Lett., 32, L18701, doi:10.1029/2005GL023684.

Yonghong, Y., W. Perrie, W. Zhang, and J. Jiang, 2008: Characteristics of Atmosphereocean interactions along North Atlantic extratropical storm tracks. J. Geophys. Res., 113, D14, doi:10.1029/2007JD008854.

Yoo, J. H., and I. Kang, 2005: Theoretical examination of a multimodel composite for seasonal prediction. Geophys. Res. Lett., 32, L18707, doi:10.1029/2005GL023513. 